\title{
Sensory Approach to Self-Regulation for Adolescent Survivors of Sex Trafficking: An Occupational Therapist's Perspective
}

\author{
Elyse Harmon \\ University of St. Augustine for Health Sciences \\ DOI: https://doi.org/10.46409/sr.FVVV9088
}

Follow this and additional works at: https://soar.usa.edu/capstones

Part of the Clinical Psychology Commons, Occupational Therapy Commons, Psychiatric and Mental Health Commons, and the Somatic Bodywork and Related Therapeutic Practices Commons

\section{Recommended Citation}

Harmon, E. (2020). Sensory Approach to Self-Regulation for Adolescent Survivors of Sex Trafficking: An Occupational Therapist's Perspective. [Doctoral project, University of St Augustine for Health Sciences]. SOAR @ USA: Student Capstone Projects Collection. https://doi.org/10.46409/sr.FVVV9088

This Capstone is brought to you for free and open access by the Student Research at SOAR @ USA. It has been accepted for inclusion in Student Capstone Projects by an authorized administrator of SOAR @ USA. For more information, please contact soar@usa.edu, erobinson@usa.edu. 
SENSORY APPROACH TO SELF-REGULATION FOR ADOLESCENT SURVIVORS OF SEX TRAFFICKING: AN OCCUPATIONAL THERAPIST'S PERSPECTIVE

\author{
Elyse J. Harmon
}

Department of Occupational Therapy, University of St. Augustine for Health Sciences

\author{
A Capstone Presented in Partial Fulfillment \\ of the Requirement for the Degree of \\ DOCTOR OF OCCUPATIONAL THERAPY \\ University of St. Augustine for Health Sciences
}

December, 2020 


\title{
Sensory Approach to Self-Regulation in Adolescent Survivors of Sex Trafficking: An Occupational Therapist's Perspective
}

\author{
Elyse J. Harmon
}

Occupational Therapy, University of St. Augustine for Health Sciences

has been approved

December, 2020

APPROVED:

Susan MacDermott, OTD, OTR/L, Doctoral Coordinator

Becki Cohill, OTD, OTR/L, Doctoral Coordinator

Erin Schwier, EdD, OTD, OTR/L, Program Director

ACCEPTED AND SIGNED:

Susan MacDermott, Digitally signed by Susan MacDermott,

Susan MacDermott, OTD, OTR/L $\mathrm{DN}$ : Cn=Susan MacDermott, OTD, OTR/L, o,

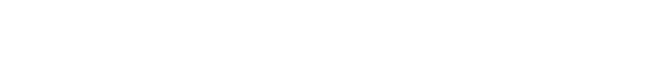

Susan MacDermott, OTD, OTR/L, Doctoral Coordinator

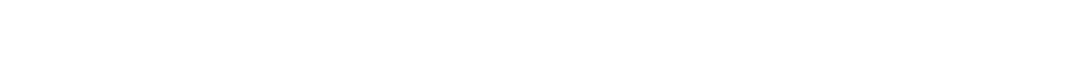
Date: 2021.05.07 14:56:27-06'00'

Becki Cohill, OTD, OTR/L, Doctoral Coordinator

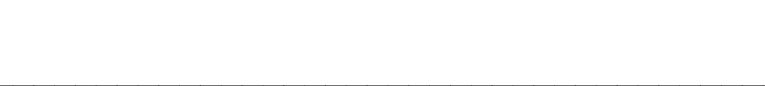

Erin Schwier, EdD, OTD, OTR/L, Program Director 
Copyright (C) Elyse J Harmon, 2020 all rights reserved 
Table of Contents

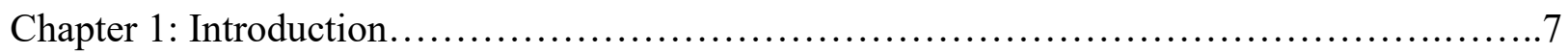

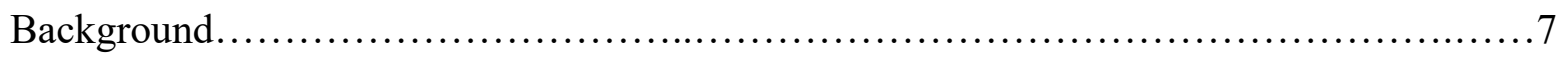

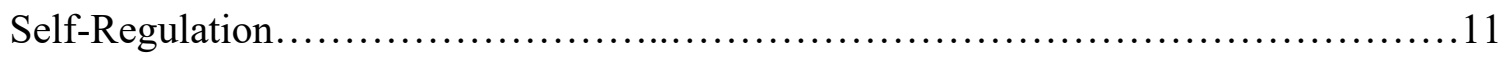

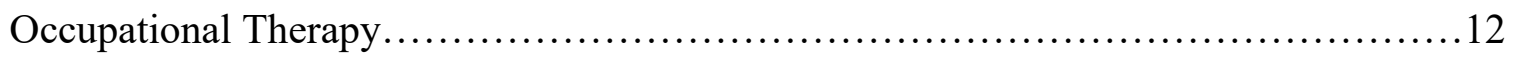

Theoretical Application........................................................

Model of Human Occupation...............................................12

Sensory Processing .........................................................13

Statement of the Problem.............................................................. 14

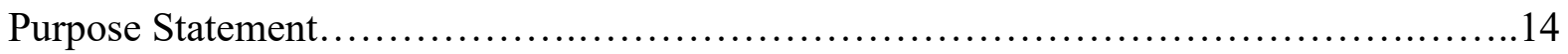

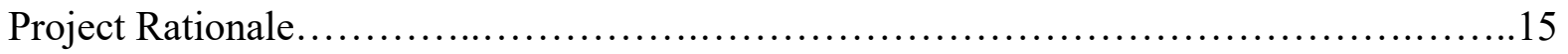

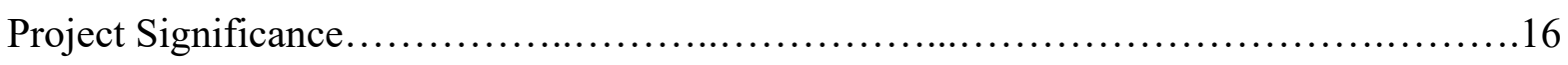

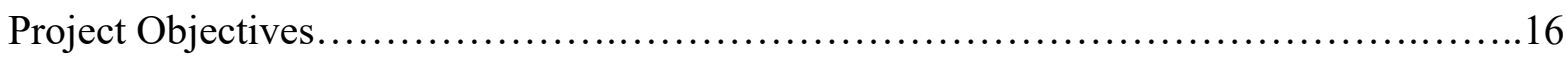

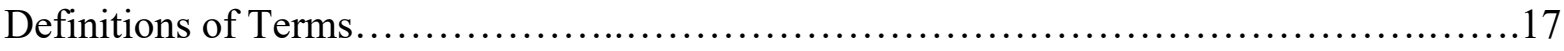

Assumptions........................................................................

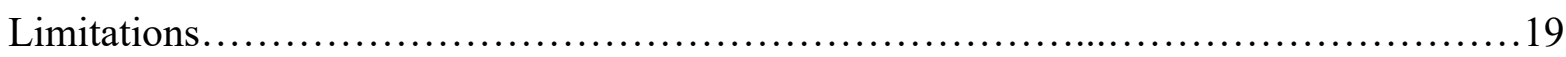

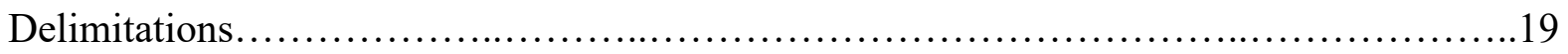

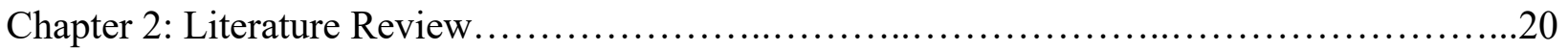

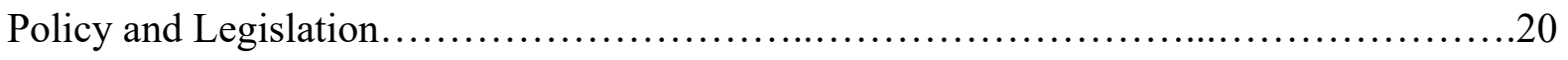

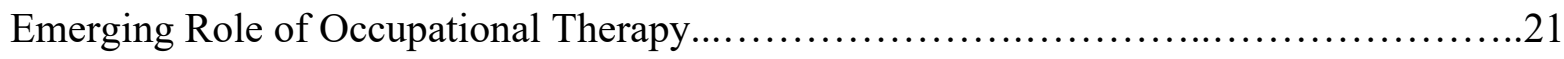

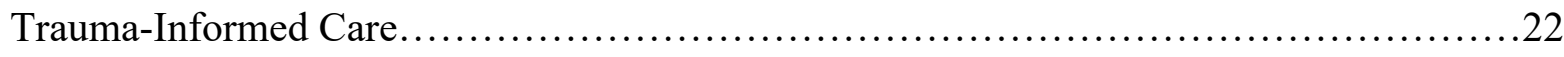

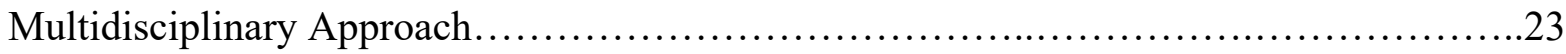

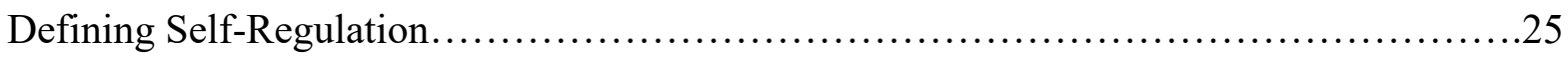

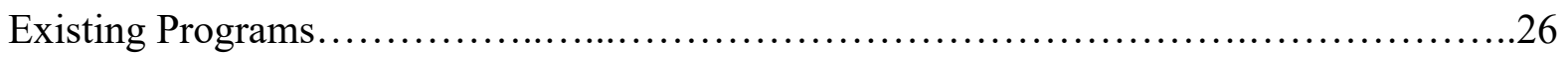


Sensory Modulation in Mental Health.................................................

Role of the Autonomic Nervous System...............................................32

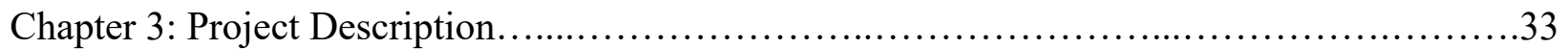

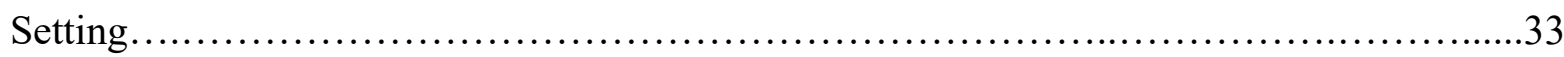

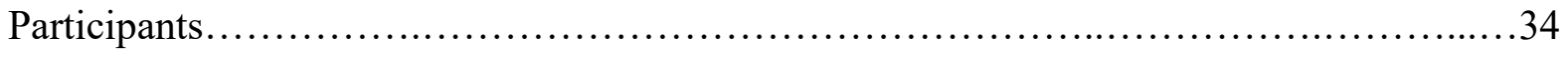

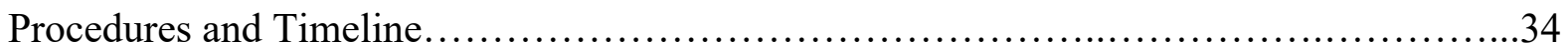

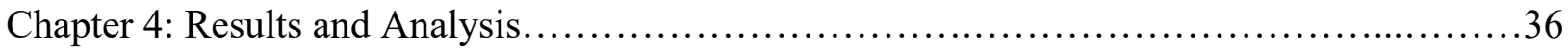

Sleep Preparation and Participation............................................................. 36

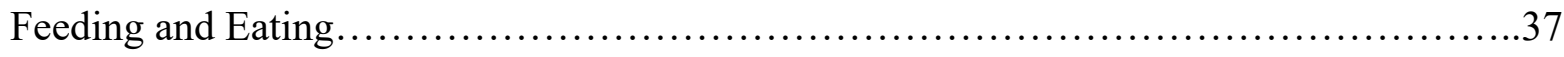

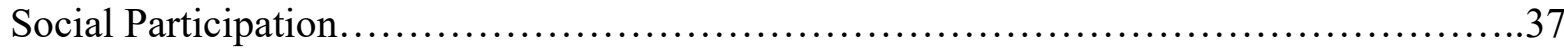

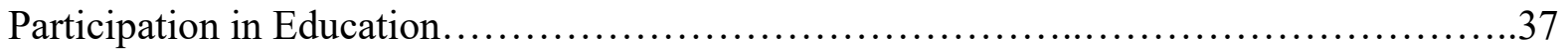

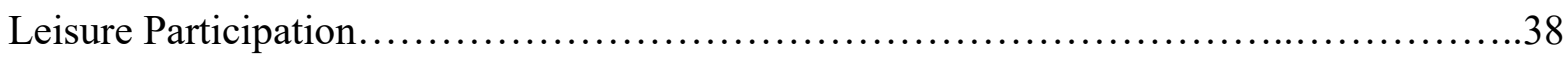

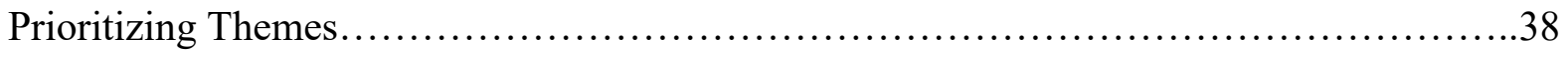

The Role of Routine for Arousal Regulation..............................................39

Need for Self-Regulation Training ....................................................

Program Planning Model.............................................................. 40

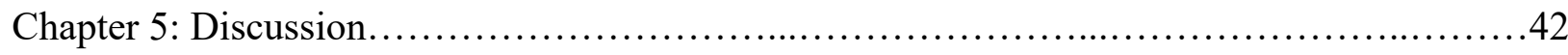

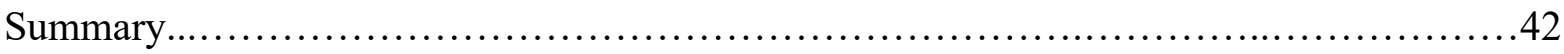

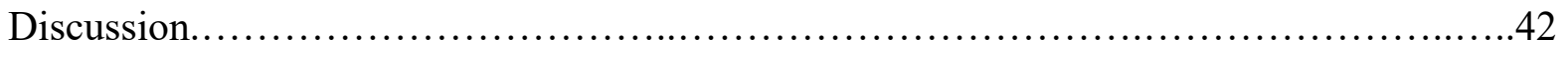

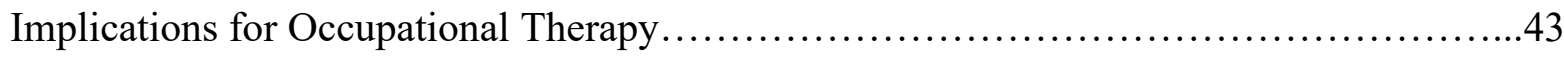

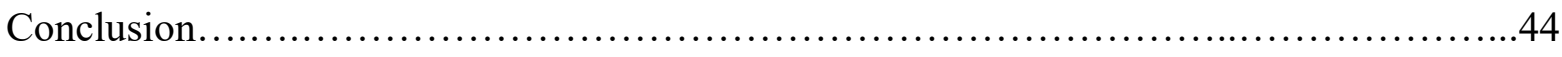

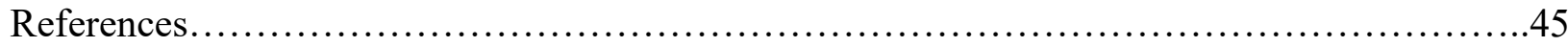

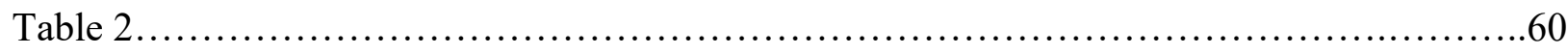

Appendix A - Clinical Observation Field Notes.............................................63 


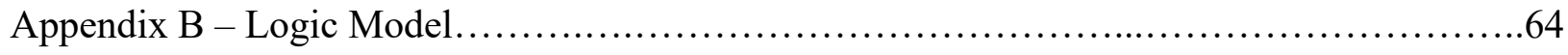

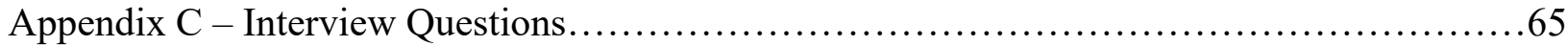

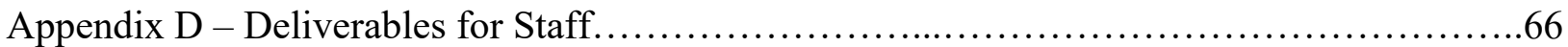




\section{Sensory Approach to Self-Regulation for Adolescent Survivors of Sex Trafficking}

The purpose of this capstone is to support community reintegration for adolescent survivors of sex trafficking (SST) through the development of sensory-based programming that fosters self-regulation, a skill necessary for occupational participation.

\section{Background}

Human sex trafficking is defined as the "recruitment, harboring, transportation, provision, or obtaining of a person for the purpose of a commercial sex act" through the use of force, fraud, or coercion (Trafficking Victims Protection Act, 2000, section 103). In cases where the individual is under the age of 18 force, fraud, or coercion is not needed to be considered sex trafficking (Trafficking Victims Protection Act, 2000). Estimates indicate 4.5 million victims of sex trafficking globally, with 98\% being women and children (Orme \& Ross-Sheriff, 2015). According to the National Human Trafficking Hotline (2018), 6,081 cases of sex trafficking were reported in 2017, with approximately 1,000 in California. This statistic is strikingly modest, as most cases go unreported. In many instances, the individuals do not self-identify as a victim (Clawson et al., 2009). Other SST are hesitant to come forwards due to stigma, lack of trust, fear of retaliation from their perpetrator, or the shame and stigma that surrounds trafficking (Clawson et al., 2009). Hesitancy in revealing the extent of their exploitation to law enforcement creates many challenges in identifying victims, intervening on their behalf, and prosecuting traffickers (Baldwin et al., 2011; Lavoie et al., 2019; Lindholm et al., 2014). Adding to the complication, many victims are brought through the criminal system and faced with charges of suspected delinquency, drug procession, and crime and are treated as a suspect or criminal rather than a victim of trafficking, which further adds to inaccurate data collection. Limited existing data is not readily accessible to academics, practitioners, and policy makers, due to privacy and civil liberty concerns (Counter-Trafficking Data Collaborative, 2018). 
Although accurate data to describe the incidence and prevalence of trafficking is not available, the literature does identify common phenomena in survivors of sex trafficking. Adolescents who have experienced commercial sexual exploitation often face lingering emotional, developmental, psychological, and behavior dysregulation (Cole et al., 2016). Individuals suffer from the highest levels of anxiety soon after they are freed from trafficking and are reintegrating into daily life (Deshpande \& Nour, 2013). A study by Macy and Johns (2011) reported that $52 \%$ of trafficking survivors continued to experience 10 or more mental health symptoms 30 days after they were freed. Survivors tend to be psychologically and emotionally distressed, leading to diagnoses of post-traumatic stress disorder, depression, and acute anxiety (Desphande \& Nour, 2013; Hossain et al., 2010; Tsutsimi et al., 2008). Additional reported mental health signs and symptoms include insomnia, suicidal ideation, substance abuse, hostility, alienation, disorientation (Maney et al., 2011; Oram et al., 2012; Zimmerman et al., 2006) along with emotional and developmental dysregulation (Cole et al., 2016). Survivors may experience difficulty with emotional regulation, feeling regularly angry or upset paired with feelings of hopelessness (Clawson et al., 2009). Furthermore, SST may experience challenges with concentration and reasoning, while finding it difficult to relax due to frequent nightmares and various sleep disorders (Clawson et al., 2009). These findings result in SST experiencing diminished occupational performance and long-term instability, matched with somatic and behavioral conditions (Cerny, 2016; Crawford \& Kaufman, 2008). One study reports that women with a history of being sex trafficked were "more isolated, had higher levels of fear, more severe trauma, and greater mental health needs than other victims of crime" (Dovydaitis, 2010, para 9). Traffickers or perpetrators often control a victim's instrumental activities of daily living (IADLs) in order to decrease independence and autonomy (American Occupational Therapy Association [AOTA], 2014; Martin, 2015). SST often endure economic exploitation as a means 
of control by their traffickers. Escape attempts, perceived misbehavior, tardiness, or noncompliance can lead to financial punishment (Belser et al., 2005; Zimmerman et al., 2011). Financial arrangements are almost always managed exclusively by the perpetrator (Zimmerman et al., 2008). Traffickers often use deceiving accounting measures and enforce inflated repayment obligations which leave victims struggling to afford basic hygiene and nutrition along with limited access to safe housing, transportation, and medical care (Zimmerman et al., 2008). When survivors leave their traffickers, they are faced with managing finances, paying rent, and accessing community services on their own for the first time.

Social isolation is a way that traffickers diminish autonomy, complicate the trauma bond, and ensure dependency for all physical and emotional needs. In a 2008 study by Zimmerman et al., $76 \%$ of trafficked women stated they were never "free to go where they wanted, or do as they wished," and 10\% reported they seldom were able to do so. Those who reported sometimes expounded by saying they could only do so if someone in authority was with them at all times (Zimmerman et al., 2008). This restraint of external engagement is achieved through confinement, surveillance, and scheduling which takes away the opportunity for victims to develop autonomy and self-esteem, leading to feelings of helplessness and shame (Zimmerman et al., 2008). Reports show that traffickers often limit interpersonal contact to family and friends along with denied access to each individual's ethnic or religious community (Zimmerman et al., 2008). Over time, social isolation becomes normalized and survivors feel relatively comfortable, safe, and trusting of the trafficker over that of law enforcement, family, and other relationships (Reid, 2016). The development of a trauma bond through social and emotional exploitation impacts their notion of what is safe and unsafe, therefore confusing psychosocial connections and relationships (Sanchez et al., 2019). The lack of opportunity to engage in healthy community-based social interactions may lead to isolation, mistrust of others, social withdrawal, 
and difficulty developing healthy relationships, each of which leaves them vulnerable to retrafficking and re-entry into high-risk situations (Zimmerman et al., 2008).

A recent national report showed that $62 \%$ of those involved in the sex trade had previously tried to leave "the life," and another majority stated they would not know how to leave even if they wanted to (Swaner et al., 2016). This startling statistic shows the challenges survivors face as their forced codependency and trauma bonding hinder their ability to foster autonomy in judgement and thought. Traffickers may take away choices within activities of daily living (ADLs) including decisions of when and where to eat, sleep, speak, and work (Evans, 2019). Once separated from their trafficker, survivors are faced with a new independence that can present challenges as their preexisting roles, routines, and identity are suddenly nonexistent. Traffickers implement a multitude of control tactics to maintain authority over their victims. Apart from physical, emotional, and sexual abuse and manipulation, these tactics may include false promises, restriction of movement, threats, and psychoactive substances (CounterTrafficking Data Collaborative, 2018). Provision of drugs followed by the withholding of those substances are used as control tactics by traffickers, causing many survivors to struggle with addiction while also posing a familiar means to cope after leaving the life (Macy \& Johns, 2011). SST also face legal insecurity through confiscation of passports and important documents by their perpetrators, leading to reduced access to healthcare and other community services in order to reduce the possibility of detection (Zimmerman et al., 2008). This deepened dependency drives survivors to more compliant obedience and agreement to dangerous work proposals (Zimmerman et al., 2008). Their vulnerability and lack of exposure to typical daily life encounters hinder SST from mastering essential life skills such as initiation, problem solving, and abstract thinking skills. 
Practical needs include housing, financial assistance, formal education, and life and job skills training (Clawson \& Dutch, 2008; Clawson et al., 2003; Maney et al., 2011). Survivors may present with challenges in "self-care, money management, home management, child care, employment, task initiation, use of public transportation, social participation, along with healthy coping and relaxation skills" (Helfrich et al., 2006). Occupational therapy can play an essential role in SST rehabilitation they are trained to address such skills (Helfrich et al., 2006).

\section{Self-Regulation}

Adolescent SST in particular are susceptible to being in a continual dysregulated arousal state due to lack of mastery in self-regulation (Koomar, 2009). During the trafficking experience, many adolescent SST are deprived of opportunities that foster essential regulatory capacities foundational for occupational engagement and therefore successful community reintegration. The ability to control one's bodily state of alertness, termed self-regulation, is a skill developed at an early age and continually built upon through coregulation and participation in activities alongside a caregiver (Koomar, 2009). This form of arousal dysregulation can manifest through sensory sensitivities to the tactile, vestibular, or auditory systems leading to regular flight, fight, or freeze responses during everyday activities (Koomar, 2009; van der Kolk, 2005). These difficulties in self-regulation directly impact engagement in a variety of roles, routines, and meaningful occupations. Occupational therapists can foster self-regulatory skills in adolescent SST through the provision of opportunities for coregulation and mastery (Koomar, 2009).

One of the most prominent approaches in fostering self-regulation is through the application of sensory-based interventions. This sensory approach was established by occupational therapists in response to national efforts to provide more humane and trauma informed restraint (AOTA, 2015b). Occupational therapists laid a foundation in restraint reduction and self-regulation through both the identification of environmental barriers and 
creation of activities that foster skills needed for self-awareness such as emotional regulation, self-control, sensory processing, and communication (AOTA, 2015b).

\section{Occupational Therapy}

The current role of occupational therapy with SST is minimal and in need of further exploration, but has profound potential (Gorman \& Hatkevich, 2016). Ample evidence shows the effectiveness of occupational therapy with other populations that have experienced trauma (Gorman \& Hatkevich, 2016). Occupational therapists have an existing role in the recovery process of individuals experiencing combat-related post-traumatic stress disorder (PTSD), homelessness, domestic violence, natural disasters, and terrorist attacks (Gorman \& Hatkevich, 2016). Secular literature supports a multidisciplinary and trauma-informed approach towards assisting SST as they transition out of trafficking and back into society, as they present with new roles and new challenges in which they often are not given the support they need to thrive autonomously (Judge, 2018). Gorman and Hatkevich (2016) argue that occupational therapy should have a role in piloting occupation-based programs and interventions for survivors, even though the evidence-based literature is limited in the support of interventions and programs within this population. Occupational therapists are skilled in physiological, cognitive, and psychosocial rehabilitation and are competent in evaluating and addressing occupations throughout the lifespan (AOTA, 2014). Furthermore, occupational therapists are knowledgeable regarding body functions and structures, human development, human behavior, sociocultural and diversity factors, performance of daily life activities, evaluation, and intervention planning (Accreditation Council for Occupational Therapy Education, 2011).

\section{Theoretical Application}

\section{Model of Human Occupation}


The Model of Human Occupation (MOHO) proves to be a useful tool in understanding how survivors are motivated and empowered to master tasks within their environment. This model emphasizes the influence of the environment, not only as one's source of motivation, but also in patterns of behavior and performance (Kielhofner, 1985). For many SST, their past interactions with the environment have been void of support for their success and independence. Perpetrators isolate and manipulate their victims into thinking that they are unable to live outside their care, robbing them of financial independence, restricting social activity, and slowly making their world smaller (Lloyd, 2012). MOHO asserts that humans can change based on factors of the environment, and that a person's thoughts, emotions, and actions are a result of how they interact with their surrounding environment (Kielhofner, 1985). Knowing that a shift in a person's internal or external structure will create a shift in their thoughts, feelings, and behaviors (Kielhofner, 1985) is groundbreaking for trauma-informed care.

Secondly, MOHO asserts that identity is shaped through a person's participation in occupations (Kielhofner, 1985). Many adolescent survivors have not experienced repetitive success in a multitude of occupations, thus hindering their development of a healthy occupational identity, which serves as a means of self-definition and a guide for future action. MOHO further states that people generate an awareness of their occupational competence when they are able to engage in productive and meaningful tasks. Thus, the goal of the proposed program will be to build up occupational competence to engage in productive and meaningful tasks. The program influenced by $\mathrm{MOHO}$ will provide the adequate repetition and environmental feedback necessary to integrate new performance patterns into daily routines.

\section{Sensory Processing}

Dunn's (2014) sensory processing model provides additional insight into how adolescent SST can effectively engage in daily occupations and communicate their environmental needs 
based off their interaction with sensory stimuli. This model addresses the relationship between neurological thresholds for incoming sensory input and the resulting behavioral response (Cole $\&$ Tuffano, 2008). According to Dunn's sensory processing model, an individual's reaction to daily sensory input is indicative of a high or low neurological threshold and a passive or active behavioral response (Ismael, 2018). Understanding their sensory preferences and tendencies can encourage SST to avoid or intensify specific sensory stimuli to sustain a calm, attentive, and alert level of nervous system arousal (Willis, 2017) therefore improving their occupational participation and engagement in meaningful roles and routines (Champagne et al., 2015). AOTA states that difficulties in modulating sensory input can negatively impact "self-concept, emotional regulation, attention, problem solving, behavior control, skill performance, and the capacity to develop and maintain interpersonal relationships" (2017, p. 1). Further research has shown that these challenges can negatively affect their capacity to "parent, work, or engage in home management, social, and leisure activities" (AOTA, 2017, p. 1). Applying these principles found in Dunn's sensory processing model, occupational therapists may utilize remedial interventions, accommodations and adaptations, sensory diet programs, environmental modifications, and education to improve occupational participation in adolescent survivors of sex trafficking.

\section{Statement of the Problem}

Current programming for adolescent survivors of sex trafficking fail to recognize how trauma impacts autonomic arousal and the ramifications this has on occupational participation. There is a gap in available programming for adolescent SST that applies evidence based sensory strategies that facilitate self-regulation, a skill foundational for lifelong occupational engagement.

\section{Purpose Statement}


The purpose of this project is to support community reintegration for adolescent survivors of sex trafficking through the development of sensory-based programming that fosters selfregulation skills needed for occupational engagement. A needs assessment of adolescent survivors living at a short term residential therapeutic program (STRTP) will be conducted to understand how challenges in self-regulation impact occupational participation. A detailed proposal will be developed for the inclusion of sensory-based programming to meet the needs identified and support lifelong occupational engagement.

\section{Project Rationale}

The literature asserts a pressing need for innovative and trauma specific treatment models for adolescents with complex trauma backgrounds in residential settings (Warner et al., 2013). A trauma informed framework offers an essential foundation in residential settings but detailed interventions that address the lasting effects trauma has on the body and the impact this has on daily life are needed to ensure comprehensive healing (Ford \& Blaustein, 2013; Hodgdon et al., 2013; Warner et al., 2013). Warner et al. (2013) advocates for the creation of new empirical and evidence based sensory motor approaches in treating affect and behavior dysregulation as seen in adolescents with trauma backgrounds in residential settings in order to improve occupational participation. Occupational therapists are equipped to address the arousal dysregulation that is the root of behavior dysregulation seen in traumatized individuals (Warner et al., 2013) while analyzing how it impacts meaningful daily life activities. Warner et al. advocates for the prominent role of occupational therapists in developing such programming, as they are knowledgeable not only in the sensory and motor systems, but also in sensory modulation strategies as they relate to arousal (Warner et al., 2013) and the impact this has on occupational participation. Thus, programming that uses sensory-based strategies to teach self-regulation will foster independence, improve quality of life, and facilitate greater engagement in meaningful 
activities of daily living, each of which is a foundational goal of occupational therapy (AOTA, 2015a).

\section{Project Significance}

Self-regulation forms an essential foundational skill for adolescent SST. By understanding their sensory preferences and tendencies, SST can learn initial steps in managing specific sensory stimuli to sustain a calm, attentive, and alert level of nervous system arousal as a base for improving occupational participation and engagement in meaningful roles and routines (Champagne et al., 2015; Willis, 2017). By addressing arousal from a sensory perspective, this project will serve to empower adolescent SST in engaging in meaningful activities that support their role and independence as thriving members of their community. This project also aims to contribute to and broaden the role that occupational therapy can have with SST throughout the reintegration process, emphasizing the importance of a multidisciplinary approach.

\section{Project Objectives}

1. Identify the current role of sensory-based approaches with survivors of sex trafficking.

2. Complete training and attend courses on trauma informed care.

3. Become familiar with the literature on the impact of trauma on arousal as it relates to occupation.

4. Observe current programming and participate in daily occupations with survivors.

5. Conduct a needs assessment through observations, interviews, and interactions in order to identify occupational needs.

6. Interview case workers, child psychologists, teachers, volunteers, and staff members to better understand how the sensory preferences of SST impact performance patterns and participation in daily activities.

7. Interview occupational therapists using sensory modulation with SST. 
8. Develop a proposal for the inclusion of skilled occupational therapy services that use a sensory-based approach to teach self-regulation.

\section{Definitions of Terms}

Occupational therapy is a profession that helps people across the lifespan be independent in the things they want and need to do in the midst of an injury, illness, or disability (OTPF, 2014). It involves the therapeutic use of everyday activities to develop or regain skills in order to improve occupational engagement in settings such as the home, school, or community (OTPF, 2014). Occupational therapy takes a wholistic approach by considering the psychological, physical, emotional, and social components that impact meaningful engagement in daily life (OTPF, 2014).

Survivor is a term given to individuals who have come out of sex trafficking and are in the midst of the recovery process. This term is used by service providers to highlight the strength and bravery of these individuals and is used in place of the term victim as a means of empowerment.

A Commercial Sex Act is any sex related activity in which something of value is given to or received by any person (Clawson et al., 2009; Trafficking Victims Protection Act, 2000). This may include pornography, exotic dancing, stripping, sex tourism, prostitution, live-sex shows (Clawson et al., 2009; Deshpande \& Nour, 2013), or escort in exchange for food, shelter, transportation, or anything else of value.

Activities of Daily Living (ADLs) are activities intended to take care of one's own body. They are essential to wellness and survival (AOTA, 2014). They include occupations such as bathing, dressing, eating, functional mobility, sexual activity, along with personal hygiene and grooming. 
Instrumental Activities of Daily Living (IADLs) are activities that sustain daily life inside the home and the community. They typically necessitate interactions that are more complex than those in ADLs (AOTA, 2014). IADLs consist of occupations such as financial management, care of others, meal preparation, religious expression, community mobility, and home management.

Reintegration is the transition process that takes place the moment SST are freed from trafficking and continues until they are assimilated back into community. Reintegration is complete when the survivor is "an active member of that society from a legal, social, economic, educational, and cultural perspective" and once they self-identify as oriented and established (Talens \& Landman, 2003, p. 8).

Trauma Bonding is the emotional attachment that grows between two people in the presence of one inflicting harassment, beatings, threats, abuse, or intimidation on the other. This relationship leads to a misperception of kindness, intimacy, safety, and love (Sanchez et al., 2019).

Self-Regulation in the context of this capstone is "the ability to attain, change, or maintain an appropriate level of alertness for a task or situation" (Williams \& Shellenberger, 1994, p. 3). Conceptualization of this term varies across contexts but for the purpose of this capstone selfregulation is the autonomic process as it relates to arousal (Grenier et al., 2003; Martini, 2005).

Hyperarousal is a heightened physiological state following activation of the sympathetic nervous system. This elevated arousal state is optimal for engaging in activities such as dancing, hiking, or playing in a sporting event. 
Hypoarousal is a diminished physiological state following activation of the parasympathetic nervous system. Hypoarousal is indicative of a low arousal state and is essential for occupations such as sleep and rest.

\section{Assumptions}

It is assumed that adolescent SST are experiencing challenges in managing arousal levels that directly impact the quality of occupational participation. Another assumption is that adolescent SST will be open and communicative regarding their needs and experiences throughout the reintegration process. Additional efforts will be made to establish rapport by participating in occupations with clients to adapt for their needs. There is an assumption that this population of SST is representative of most survivors in similar contexts. There is also an assumption that adolescent SST can identify how occupational therapy services benefit their daily lives distinctive from medications, therapy, and any other services or factors during reintegration. It is assumed that current support throughout the reintegration process does not address all needs and that adolescent SST will be receptive to and motivated to carry out occupation and sensory-based programming.

\section{Limitations}

Limitations to this project include the inability to isolate occupational therapy services, as many adolescent SST in residential programs will be receiving other therapies and services during their stay. Due to the complexities and nature of trauma, survivors may need more than 14 weeks (the capstone experience timeframe) to establish a trusting relationship in which they feel comfortable exposing profound needs and in turn taking active steps towards reintegration, therefore presenting another limitation. Additionally, the type of trafficking and stage of recovery will vary depending on the participants at the site.

\section{Delimitations}


A delimitation of this project can be found within the nature of qualitative methods. Information will be gathered from semi-structured interviews and observations which are subjective in nature. Assessments of sensory-based needs will focus on perception, and not objective measures. Additionally, information will be gathered from within the context of a STRTP and therefore limits assessment of survivors in a variety of contexts and environments.

\section{CHAPTER II: Literature Review}

This chapter explores common themes found in the literature in an effort to identify the unique role that occupational therapy can have in implementing sensory-based approaches with adolescent SST. The evidence is classified into the following themes: Policy and Legislation, Emerging Role of Occupational Therapy, Trauma Informed Care, Multidisciplinary Approach, Defining Self-Regulation, Existing Programs, Sensory Modulation in Mental Health, and Role of the Autonomic Nervous System.

\section{Policy and Legislation}

Laws at both the state and federal levels establish trafficking as a crime and protect victims of trafficking. The Trafficking Victims Protection Act (TVPA) passed in 2000 provides a national framework to protect trafficking victims, prosecute their perpetrators, and prevent further trafficking (United States Department of State [USDOS], 2000). Thompson (2017) emphasizes that this reform in legal status away from criminal and prostitute and towards victim and survivor is an essential step in better identification and ongoing support of victims. Under the TVPA is a 3P paradigm approach that establishes prevention, protection, and prosecution as the national response towards human trafficking (USDOS, 2000). Since 2000, U.S. Congress has passed Trafficking and Violence Protection Reauthorization Acts of 2003, 2005, 2008, 2013, and 2017 (National Human Trafficking Hotline, 2014). 


\section{Emerging Role of Occupational Therapy}

The United Nations Office on Drugs and Crime (UNODC) created the Model Law against Trafficking in Persons (UNODC, 2009). Within this model, occupational therapy is listed as a means of rehabilitative compensation that each individual state should provide for survivors of human trafficking (UNODC, 2009). Convicted traffickers can be mandated to provide this compensation, but since most traffickers are incarcerated or avoid detection from law enforcement, many victims do not receive restitution (Thompson et al., 2020; UNODC, 2009)

In a societal statement published by The American Journal of Occupational Therapy, Bryant et al. contends that occupational therapy should have a role in piloting occupation-based programs and interventions for survivors, as the literature lacks support of interventions and programs that are built upon evidence-based practice within this population (2015). Occupational therapy has a role in identifying and working through both the intrinsic and extrinsic obstacles that impact one's well-being and occupational engagement, which make them qualifying practitioners in working with this population (Cerny, 2016). The literature details the potential role of occupational therapy in combatting human sex trafficking and acknowledges the current role as minimal and underdeveloped (Gorman \& Hatkevich, 2016).

AOTA outlines the role of occupational therapy in the promotion, prevention, and intervention of youth and childhood trauma within mental health settings (2015). Occupational therapists trained in both trauma and sensory-based interventions can deliver trauma-informed sensorimotor arousal regulation interventions in collaboration with mental health professionals (AOTA, 2015a; LeBel \& Champagne, 2010; Warner et al., 2014). Occupational therapists can pair sensory and cognitive approaches to teach traumatized individuals to calm their bodies and physiological responses (AOTA, 2015a). Additional mindfulness and coping strategies can be 
used to reduce stress in the midst of overwhelming situations (AOTA, 2015a). Additionally, occupational therapists can facilitate environments that provide opportunity for mastery, connection, and resiliency in the traumatized individual (AOTA, 2015a). AOTA policies also suggest incorporating group interventions to address self-regulation and sensory modulation (2015). Various self-awareness tools can be used to teach children emotional regulation strategies (AOTA, 2015a). Furthermore, educating staff and caregivers on the importance of emotional and co-regulation is another component of the role of occupational therapy with traumatized youth as outlined by AOTA (2015a). AOTA policies indicate that occupational therapists have education in neuroscience, anatomy, and activity and environmental analysis that aid in the recognition and treatment of occupational performance issues that result directly from challenges in modulating sensory input (2015a).

The use of sensory-based approaches that focus on addressing the physiological ramifications of trauma and its impact on occupation is an evidence-based practice grounded in occupational therapy research (LeBel et al., 2010; Moore \& Henry, 2002; Smith et al., 2005). Occupational therapists have addressed autonomic hyperarousal and self-regulation in patients with other trauma backgrounds by applying strategies grounded in sensory-based theories (Stoller et al., 2012). Occupational therapists have a role in considering how an individual's sensory preferences and tendencies influence their activities of daily living and participation in meaningful occupations. There is ample evidence to support the benefits of sensory-based approaches, but few programs apply this knowledge to support occupational participation.

\section{Trauma-Informed Care}

Trauma-informed care (TIC) is a practice framework designed to guide treatment delivery through an understanding of how trauma influences one's perception of physical and emotional safety, sensations, behaviors, and relationships (LeBel et al., 2010; National 
Association of State Mental Health Program Directors, 2009). TIC minimizes re-traumatization by providing evidence-based assessment and treatment (AOTA, 2015a) and acknowledging the neurophysiological state that leave individuals vulnerable to functional and behavioral problems (LeBel et al., 2010). Practitioners providing TIC understand the relationship of the stress response on survival and the ability to feel safe. Through an individualized and client-centered approach, TIC seeks to reestablish a perception of safety and stability to create a more controlled and functional state in the individual (Champagne \& Stromberg, 2004, LeBel et al., 2010). This return to a regulated state leads to greater occupational participation and engagement in meaningful life roles, which is why TIC has a prominent role in occupational therapy practice (LeBel et al., 2010).

\section{Multidisciplinary Approach}

Both traditional and modern trauma treatment have largely neglected to help individuals safely experience their sensations (van der Kolk, 2015). Medications that target the autonomic nervous system (ANS) are prescribed to decrease hyperarousal and stress responsivity, but these medications also block chemicals that are essential to engagement, motivation, and pleasure (van de Kolk, 2015). In psychotherapy, the most commonly used evidence-based therapeutic treatments for SST include cognitive therapy, cognitive behavioral therapy, and exposure therapy (Williamson et al., 2008). Additional approaches include psychodynamic psychotherapy, group therapies, and dialectical behavior therapy (Warner et al., 2013). Each of these approaches are crucial to the processing of trauma, but these language-based therapies rely on verbal processing and cognitive strategies (LeBel et al., 2010; Warner et al., 2013) and lack techniques that address the physiological responses (LeBel et al., 2010). In order for these talk-based therapies to work, the individual must first be adequately regulated and organized, or they will be unable to access higher order brain functions needed for language and symbolic expressive function (Warner et 
al., 2013). In a study of women with histories of childhood sexual abuse and PTSD, brain imaging revealed a decrease in brain activation of Broca's area, the part of the brain involved in speech production, following a traumatic trigger (Shin et al., 1999). This finding provides reasoning as to why individuals with PTSD may have a hard time engaging in dialogue while thinking about a triggering event that places them in autonomic hyperarousal (Shin et al., 1999; van der Kolk, 2004). This line of reasoning offers further support to the development of supplemental alternative approaches when working with traumatized individuals.

Additional supporting studies show that individuals with trauma backgrounds have an increase in neurophysiological reactivity that considerably hinders both processing and learning, providing reasoning as to why talk-based therapies as best applied within a multidisciplinary approach (LeBel et al., 2010; Ogden \& Minton, 2000; van der Kolk, 2004). Furthermore, verbal processing alone "can't integrate the disorganized sensations and action patterns that form the core imprint of trauma" (LeBel et al., 2010; van der Kolk, 2004; Wylie, 2004, p.5). In response to this awareness, emerging trauma treatment is incorporating specific and deliberate physical movement into the treatment plan for individuals with PTSD (LeBel et al., 2010; Levine, 1997; Ogden \& Minton, 2000; van der Kolk, 2004). Alternative treatments such as eye movement desensitization and reprocessing along with sensorimotor processing have endeavored to address the somatic and whole-body repercussions of trauma (Fisher, 2005; LeBel, 2010; Ogden \& Minton, 2000). Although disciplines such as psychiatry and psychology have begun to acknowledge the role of affect regulation, treatment modalities have not yet been developed that focus on foundational components of regulation (Warner et al., 2013). Another source in the occupational therapy literature states that despite the growing awareness of the repercussions trauma has on "brain development, neurobiology, and the general physiological response" (LeBel, 2010, para 1), the development of interventions that directly confront the 
neurophysiological impact trauma has on the body are scarce (Fisher, 2005; van der Kolk, 2004, 2006).

In summary, a multidisciplinary and holistic approach to trauma treatment in SST is necessary and supported by the literature. Psychology, social work, occupational therapy, and nursing all have a prominent role in the community reintegration process of SST (Bent-Goodley, 2019; de Chesnay, 2013; Williamson et al., 2008). Sensory and occupation-based programming administered by occupational therapists that addresses the role of arousal following trauma is a viable and evidence-based treatment approach that should be done in adjunction with other mental health providers and established trauma treatment in order to improve lifelong participation in meaningful occupations.

\section{Defining Self-Regulation}

Self-regulation is understood in the context of a variety theoretical frameworks which adds to an ambiguity of definitions not only across professions, but amidst occupational therapy literature and practice. In the occupational therapy literature for adolescent and school aged children, self-regulation is defined and understood through the sensory integration theory framework (Martini et al., 2016). In this framework, occupational therapists facilitate selfinitiated or assisted sensorimotor strategies that target arousal or emotion (Martini et al., 2016). This is then paired with metacognitive techniques that offer awareness into an emotional or sensory state, such as a level of alertness or a feeling of boredom (Martini et al., 2016). With this knowledge, input in the surrounding environment can be altered such as turning on white noise or putting on a weighted blanket, so the original emotional or sensory state can be altered or maintained (Martini et al., 2016).

According to the Occupational Therapy Practice Framework (OTPF), interventions targeting self-regulation consist of deliberate actions that addresses performance skills or client 
factors (2020). This includes confronting sensory processing in order to foster emotional stability or executive functioning needed for participation in meaningful occupations (OTPF, 2020). These interventions that support occupation necessitate dynamic involvement of the individual and may incorporate various tools to connect it to occupation (OTPF, 2020).

\section{Existing Programs}

Cohannet Academy is a residential treatment program for severely traumatized adolescent girls (Warner et al., 2013). The program uses sensory-based treatment interventions to help residents manage and regulate physiological and emotional reactions to enable greater participation in daily roles and routines (Warner et al., 2013). The program not only aligns with federal agendas aimed at reducing the use of seclusion and restraint (U.S. Department of Health and Human Services, Substance Abuse and Mental Health Services Administration, 2003), but it also is in unison with the Justice Resource Institute, Massachusetts Department of Mental Health, and The Joint Commission. Sensory-motor interventions at the residential treatment program include the creation of sensory diets, toolboxes, and sensory rooms where residents can nurture skills that can be used when in a high arousal state (Warner et al., 2013). Residents also were a part of making individualized "plans for safety" where different up and down regulation strategies were identified (Warner et al., 2013). Much of the focus was on practicing these up and down regulation strategies in the sensory room. There was a $68 \%$ reduction in restraints within the first year of sensory modulation programming, followed by $25 \%$ and $3 \%$ in the years to follow (Warner et al., 2013).

Grace House is a day treatment program for young adult women who present with significant problems with self-injury, behavior dysregulation, suicidal ideation, and instability in community placements following chronic childhood trauma (Holland, 2018). The program focuses on the development of community living skills. Following the administration of the 
Adult/Adolescent Sensory Profile, the occupational therapist on staff creates individualized sensory treatment programs and sensory kits that can be used by the participants in the midst of overwhelming sensory and emotional stimuli (Holland et al., 2018). "Energy Check-ins" are a routine component of the programming, in which participants identify their current "energy number" along with a corresponding feeling (Holland et al., 2018). When low energy levels are reported, movement activities such as dancing and yoga are initiated (Holland et al., 2018). When reports of high energy states are noted, participants are encouraged to utilize sensory equipment, fidgets, a designated calm room, and other modalities to regulate their arousal level (Holland et al., 2018). The program also incorporates the self-directed use of weighted blankets and tactile feedback during participation in activities such as cooking or art-making (Holland et al., 2018). This focus on self-regulation helps the participants identify early signs of arousal dysregulation_and immediately apply modulation strategies to maintain a calm arousal state, instead of turning to self-injurious or aggressive behavior (Holland et al., 2018).

Snider (2012) developed a relaxation kit and manual to improve sleep participation and rest for domestic victims who are minors of sex trafficking residing at a safe home. The program focused on addressing symptoms of PTSD as they relate to occupation and provided trauma informed programming to safe homes and transitional programs for SST (Snider, 2012).

Sensory Motor Arousal Regulation Treatment (SMART) is an outpatient approach that blends the principles of psychotherapy and occupational therapy to treat complex trauma in children and adolescents (Warner et al., 2013). SMART talks a full-body and multisensory approach through the development of sensory rooms that encourage self-directed engagement of the proprioceptive, vestibular, and tactile sensory systems (Westcott et al., 2018). Warner et al., argue that engagement of one's sensory motor system is the gateway to emotional, psychological, and relational regulation (2013). SMART uses therapeutic equipment such as 
weighted blankets, balance beams, and large cushions to facilitate a natural and self-directed means of emotional and physiological regulation while simultaneously facilitating interpersonal connection (Westcott et al., 2018). SMART combines movement and relationship as a means to regulate arousal states.

The Sensory-Enhanced Yoga Institute pairs sensory-based occupational therapy principles with evidence in trauma psychology, neuroscience, and Eastern yoga philosophy to treat individuals healing from combat stress, sexual trauma, domestic violence, PTSD, sensory modulation disorders, anxiety, and other associated autonomic nervous system disorders (Stoller et al., 2012). Sensory enhanced yoga has been shown to be an effective treatment modality for reducing hyperarousal and improving self-regulation in traumatized individuals (Stoller et al., 2012) and is an evidence-based treatment modality when used as a preparatory or purposeful activity (AOTA, 2005). Stoller et al. published their study in The American Journal of Occupational Therapy, in which they explored the effects of sensory-enhanced hatha yoga on reducing state and trait anxiety following combat stress in deployed military personnel (2012). The yoga programming included critically detailed and structured activities that targeted autonomic nervous system dysfunction through therapeutic administration of proprioceptive input, deep touch pressure, slow rhythmical vestibular movement, along with specific yoga techniques that sought to inhibit the sympathetic nervous system leading to a calm and regulated arousal state (Stoller et al., 2012). The programming, designed by an occupational therapist, used both top-down and bottom-up methods for arousal regulation (Stoller et al., 2012). Both sensory integrative and sensorimotor treatment approaches rooted in sensory-based occupational therapy principles were used throughout program development and implementation (Stoller et al., 2012).

The Alert Program, developed by occupational therapists, is a set of strategies and activities that help individuals of all ages learn to modify their level of arousal to better engage in 
meaningful occupations (Williams \& Shellenberger, 1994). The focus of the program centers around the ability to adjust how alert one feels by altering the state of their autonomic nervous system through sensorimotor activity (Williams \& Shellenberger, 1994). The Alert Program uses the metaphor of a car engine to help individuals describe their level of arousal (low, high, or optimal arousal) and provides sensorimotor activities that help them change their arousal levels to best support occupational engagement, taking into account the demands and expectations of the environmental context (Williams \& Shellenberger, 1994).

The Zones of Regulation (Kuypers \& Winner, 2011) incorporates the foundational principles of the Alert Program and further develops a framework to help students cultivate skills needed for independent self-regulation. Similar to the Alert Program, children learn to identify their arousal state and apply sensorimotor strategies to adjust their alertness to match the demands of the given situation, a skill termed self-regulation (Kuypers \& Winner, 2011). The Zones, created by an occupational therapist in the school system, provides curriculum that teaches children and adolescents to self-regulate their sensory needs along with their emotions and impulses (Kuypers \& Winner, 2011). The Zones curriculum identifies four colored zones, each indicating a specific state of alertness. The curriculum helps students identify what zone they are in and assists them in using sensorimotor strategies to change or remain in their current zone. The Zones framework provides a model that considers underlying impairments in emotional and sensory regulation, executive functioning, and social cognition to help students learn independent self-regulation (Kuypers \& Winner, 2011).

Research on existing programs has uncovered a need for further program development addressing self-regulation from a sensory perspective for adolescent survivors of sex trafficking. Awareness and responsiveness towards the physiological response of complex trauma has led to new developments of evidence-based interventions. Despite the rise in awareness and proven 
efficacy, there is a lack of programming that use sensory-based programming to teach selfregulation in adolescent SST.

\section{Sensory Modulation in Mental Health}

Sensory modulation is both a neurological process and an intervention approach (Wallis, 2017). As a neurological process, sensory modulation is the ability to respond to incoming sensory input and regulate the resulting arousal levels in a way that matches the given situation, leading to optimal occupational engagement. As Miller et al. (2001) put it, sensory modulation as a neurological process is "the capacity to regulate and organize the degree, intensity, and nature of responses to sensory input in a graded and adaptive manner. This allows the individual to achieve and maintain an optimal range of performance and to adapt to challenges in daily life" (p. 57). As a treatment modality, sensory modulation consists of "non-invasive, self-directed therapeutic interventions (activities and modalities) offering specific amounts and types of sensory input for the purposes of fostering organization and self-regulation" (Champagne, 2015, para 7). When the frequency, type, and amount of sensorimotor input is individually and skillfully delivered, sensory modulation interventions provided by occupational therapists have the potential to substantially improve "alertness, arousal, attention, and an individual's ability to adapt and participate in meaningful life activities" (Champagne, 2015; Hanschu, 1998). The end therapeutic goal of sensory modulation is to improve self-regulation and thus the quality of engagement in meaningful roles and occupations (Champagne, 2015).

Within inpatient acute mental health settings, there has been a recent push towards more humane, trauma-informed, and therapeutic methods of de-escalation through the application of sensory modulation interventions by occupational therapists (Adams-Leask et al., 2018; Andersen et al., 2017; Bailliard et al., 2017; Champagne et al., 2003, 2004 2005, 2006, 2011, 2015; Gardner 2016; Novak et al., 2012) and nursing or other non-specified inpatient psychiatric 
professionals (Blackburn et al., 2016; Chalmers et al., 2012; Forsyth et al., 2018; Lloyd et al., 2014; Sutton \& Nicoholson 2012). However, only four studies published in the literature have used sensory modulation as a treatment modality in the outpatient setting (Champagne, 2011; Champagne et al., 2010; Pfeiffer et al., 2012; Wallis, 2018). All four studies revealed a decrease in anxiety along with increased participation in social, leisure, and work activities following sensory modulation interventions. The four interventions collectively addressed five main areas: (1) education regarding the autonomic nervous system, (2) self-advocacy, (3) sensory selfexploration, (4) sensory diet, and (5) environmental adaptations (Champagne, 2011; Champagne et al., 2010; Pfeiffer et al., 2012; Wallis, 2018).

Champagne, a researcher and occupational therapist in the mental health setting, has spent much of her professional career studying the efficacy of weighted modalities in adolescent, adult, and geriatric populations within acute mental health settings (Champagne et al., 2007). Champagne (2007) advocates for a distinction between Sensory Integration (SI) approaches and sensory modulation interventions in mental health settings. Champagne states that weighted modalities as used in mental health is considered sensory modulation due to the way it is used to facilitate self-organization (Champagne, 2005). Weighted modalities are used to facilitate selfcare, self-nurturance, and the development of coping skills (Champagne, 2007) in order to meet specific functional occupational goals (Champagne, 2015). Champagne's use of weighted blankets as a sensory modulation treatment modality has been shown to help individuals with varying mental health diagnoses attain and uphold appropriate levels of nervous system arousal (2015). This method of independent self-regulation leads to improved occupational engagement and fulfillment of meaningful life roles (Champagne, 2015). Weighted modalities such as a weighted blanket may be used as a preparatory, purposeful, and occupation-based intervention aimed at improving occupational performance and participation (AOTA, 2014; Champagne, 
2010, 2011, 2015). Other studies have found that therapeutic administration of proprioceptive input through the skilled use of weighted and inflation vests can lead to changes in autonomic arousal, decrease in impulsivity, improved attention, decrease in self-stimulatory behaviors, and improved capacity to remain focused on fine motor tasks in children with mental health diagnoses (Fertel-Daly et al., 2001; Lin et al., 2014; Olson \& Moulton, 2004a, 2004b; Reynolds et al., 2015; VandenBerg, 2001).

\section{Role of the Autonomic Nervous System}

Literature grounded in neuroscience is able to provide insight into how trauma impacts the ANS leading to challenges in sensory modulation and self-regulation. The ANS is the brain's survival system, consisting of two branches which regulate arousal throughout the body (van der Kolk, 2015). The sympathetic nervous system (SNS) is commonly referred to as the "fight or flight" and mobilization response. When presented with a threat in the form of unfamiliar or noxious stimuli, the SNS releases the neurotransmitter epinephrine, fueling the body through an increase in heart rate, expansion of the lungs, and dilation of the pupils. When the threat is no longer present, the parasympathetic nervous system (PNS) works to calm the body back to a restful state, through releasing acetylcholine. This results in digestion, reduction in pupil size, decreased heart rate, and contraction of the lungs.

According to van der Kolk (2015), when the SNS and PNS work together to appropriately activate and inhibit the release of neurotransmitters, an individual is in an "optimal state of engagement with the environment and [themselves]" (p. 268). In individuals with PTSD, the SNS and PNS are out of sync which is why they are so vulnerable to overrespond to relatively minor stresses (van der Kolk, 2015). In these individuals, their SNS is still responding even though the threat is no longer present, placing their bodies in a state of hyperarousal. When an individual is in a state of hyperarousal, they present with sensory hypersensitivity where 
stimuli such as a bright light or a car passing by can place someone in a state of panic or rage (van der Kolk, 2015). Various occupational therapy interventions have been recommended to diminish the response of the SNS in order to improve adaptation, emotional regulation, along with occupational performance and participation (Edelson et al., 1999; Fertel-Daly et al., 2001; Grandin, 1992; Mullen et al., 2008; Reynolds et al., 2015; VandenBerg, 2001).

In summary, occupational therapy has profound potential to support adolescent survivors of sex trafficking during the reintegration process. A multidisciplinary approach based in traumainformed care is central to program development. Multiple programs have focused on regulating the autonomic nervous system in individuals who have experienced trauma through sensory rooms, sensory diets, and sensory modulation interventions leading to improved occupational participation. The literature stresses a pressing need to develop occupation-based programming that takes into account how trauma and sensory input impact arousal levels and how it influences participation in meaningful activities.

\section{CHAPTER III: Project Description}

This capstone sought to support community reintegration for adolescent SST through the development of sensory-based programming that fosters self-regulation, a skill necessary for lifelong occupational engagement. A needs assessment was completed to understand how challenges in regulating their arousal levels influenced their patterns of behavior and participation in meaningful activities.

\section{Setting}

This capstone took place at a STRTP for adolescent survivors of sex trafficking. Services provided at the live-in center include counseling, therapeutic care, and education for survivors over the span of 6 months or more. 


\section{Participants}

Participants included 13 adolescent survivors of commercial sex trafficking ages 12-17 residing at the STRTP. Although it was not a requirement of the STRTP, the majority of survivors were in foster care or a part of the juvenile justice system. Additional data contributors were occupational therapists who have administered sensory-based interventions with survivors of human trafficking in other settings. Further planned contributors to data collection were staff members, social workers, a child psychologist, and teacher at the STRTP. However, due to employment changes at the site, the teacher and child psychologist were no longer accessible for interviews. Due to scheduling and their limited on-site involvement, interviewing the social workers was not realistic nor conducive to the overall project. Furthermore, the capstone student's ability to be at the STRTP was limited after 8 weeks, leading to challenges in completing semi-structured interviews with staff members.

\section{Procedures and Timeline}

The capstone timeline (see Table 1) spanned a total of 16 weeks. During the first few weeks of the capstone experience, the student focused on completing courses and training on trauma informed care and sensory-based approaches to better understand how autonomic dysregulation impacts daily life engagement. The student met with the program director at the STRTP and inquired about various occupational and sensory needs of adolescent SST. Semistructured interviews were conducted in these initial weeks with occupational therapists who had implemented sensory modulation interventions with survivors of human trafficking in other settings. During this time, the student contacted the child psychologist on site at the STRTP and began initial steps at building rapport and conveying the purpose and intent of the student's role in proposing sensory-based programming. 


\section{Table 1}

Timeline

\begin{tabular}{lll}
\hline Week & Task & \\
\hline July 27- August 7 & - & Attended courses on trauma informed care and sensory-based \\
& approaches \\
& - & Interviewed occupational therapists using sensory modulation with \\
& SST & Met with the program director and on-site child psychologist at the \\
& & STRTP \\
September 8- & - Completed on site training \\
October 9 & - Observed current programming \\
& - Participated in daily occupations with SST \\
October 12-30 & - Attended Crisis Intervention Training \\
& - Continued daily participation in occupations with SST \\
November 2-27 & - Analyzed clinical observations to determine needs of SST \\
& - Categorized needs into major themes \\
December 11-19 & - Proposed programming \\
\hline
\end{tabular}

For the next step of the capstone experience, the student spent 40 hours a week at the STRTP to conduct clinical observations and observe current programming. Due to the sensitive nature of the trauma survivors endured, the student focused on building rapport and trust with the adolescent SST through direct participation in daily activities. Each week the student immersed into the natural context and environment of the survivors to gain a comprehensive understanding of their daily routines and roles. During these daily encounters, the student gained insight into how their arousal levels, and challenges in regulating them, either helped or hindered their participation in various occupations. Examples of daily activities completed together included hiking, finishing homework in the classroom, eating meals, driving to appointments, exercising, doing laundry, and playing card games. The student conducted reflective documentation immediately after encounters to record observations, reactions, and statements during activity participation (see Appendix A). Documentation was completed in the absence of SST to ensure both confidentiality and a casual environment during interactions. 
Common themes were identified from the needs assessment at the STRTP which were further compiled into categories. The weeks that followed were focused on program development. The final outcome of the capstone was a proposal of sensory-based programming to meet the identified self-regulatory needs (see Appendix D).

\section{CHAPTER IV: Results and Analysis}

Analysis of the non-standardized and site-based needs assessment results at the STRTP clearly indicated that challenges in self-regulation interfered with positive daily occupational participation. The staff report, self-report, clinical observation, and direct participation identified six prominent occupations impacted by arousal dysregulation. These were: sleep preparation, sleep participation, feeding/eating, social participation, leisure participation, and participation in education (see Table 2).

\section{Sleep Preparation and Participation}

The first overall trend revealed by the needs assessment was that participants had compromised sleep preparation and participation resulting from challenges in self-regulation, which was further exacerbated by scheduled activities in the evening routine. There were an abundance of data from the staff and many self-reports that documented participants requiring an excessive amount of time to fall asleep each night. Additional reports indicate various participants not falling asleep until 2:00am or 3:00am on multiple occasions. Through detailed analysis, the student discovered that various activities in the evening routine led to high arousal levels at bedtime, which caused participants to struggle achieving an arousal level supportive of sleep. The final two activities before lights-out included a group meeting at 9:00pm where each participant reflected on their "highs and lows" of the day, which was followed by a 1-1 behavior review at 9:30pm. These evening activities led to heightened arousal levels and often conflict 
and aggression in many participants on a consistent basis. Although arousal was not the only barrier to sleep participation, it was a major obstacle identified through the needs assessment.

\section{Feeding and Eating}

In the areas of feeding and eating, the student observed a high rate of meal refusals. While a variety of factors were responsible for missed meals, hyperarousal was a main contributor. The majority of meal refusals occurred shortly after a house fight or crisis intervention, when arousal levels among all participants were still elevated. Other meal refusals were noted prior to important meetings, such as an upcoming court hearing, which led to significantly heightened arousal levels and made eating a difficult and undesired activity.

\section{Social Participation}

In terms of social participation, it was clearly suggested that participants had a difficult time engaging with others while in low arousal states, as they then tended to prefer isolated activities. While in high arousal states, participants had an increased incidence of social conflict and aggression. They voiced a lack of desire to be around others in escalated arousal states, which further added to social division and challenges in engaging with others.

\section{Participation in Education}

During school participation, the participants displayed behaviors indicative of both hyperarousal and hypoarousal, which led to challenges in attention and learning. A few participants struggled to attain an arousal level supportive of concentration and would fall asleep or refuse to participate altogether. The majority of students displayed high arousal levels through constant body movement, high distractibility, social conflict, aggression, along with a frequent need for staff intervention or de-escalation. The classroom environment was often loud and chaotic, which contributed to even higher arousal levels in many participants, adding another barrier to participation in education. 


\section{Leisure Participation}

Another common theme involved challenges in attaining an arousal level supportive of leisure participation. While in high arousal states, the participants frequently displayed aggressive behavior and found quiet and relaxed activities, such as reading or painting, to be challenging. While in low arousal states, engaging in physically demanding activities, such as volleyball or hiking, was challenging. This difficulty in matching their arousal levels to the demands of the activity limited their participation in leisure.

\section{Prioritizing Themes}

The student took these observations from Table 2 and further prioritized the major themes (see Table 3). Analysis focused on identifying the most prominent barriers and the impact they had on the occupation.

\section{Table 3}

\section{Prioritized Themes and Occupational Impact}

\begin{tabular}{|c|c|c|}
\hline Occupation & Barriers & Impact on Occupation \\
\hline $\begin{array}{l}\text { Sleep } \\
\text { preparation and } \\
\text { participation }\end{array}$ & $\begin{array}{l}\text { Hyperarousal } \\
\text {-lying in bed awake till 3:00am } \\
\text { Alerting activities before bedtime (phone calls, } \\
\text { group meeting, behavior review) }\end{array}$ & $\begin{array}{l}\text { Difficulty falling asleep } \\
\text { following evening } \\
\text { activities }\end{array}$ \\
\hline $\begin{array}{l}\text { Participation in } \\
\text { education }\end{array}$ & $\begin{array}{l}\text { Hyperarousal } \\
\text {-constant movement, easily distracted } \\
\text { Hypoarousal } \\
\text {-falling asleep }\end{array}$ & $\begin{array}{l}\text { Challenges in } \\
\text { concentration and } \\
\text { learning }\end{array}$ \\
\hline Feeding/eating & $\begin{array}{l}\text { Hyperarousal } \\
\text {-frequently scanning environment, tapping } \\
\text { feet, not sitting still } \\
\text { Appointments such as court hearings, calls } \\
\text { with social workers, or crisis intervention } \\
\text { surrounding mealtime }\end{array}$ & Frequent meal refusals \\
\hline $\begin{array}{l}\text { Social } \\
\text { Participation }\end{array}$ & $\begin{array}{l}\text { Hypoarousal } \\
\text {-preference for solo activities } \\
\text { Hyperarousal } \\
\text {-verbal or physical fights }\end{array}$ & $\begin{array}{l}\text { Difficulty engaging with } \\
\text { others } \\
\text { Frequent conflict or } \\
\text { aggression }\end{array}$ \\
\hline
\end{tabular}




$\begin{array}{lll}\text { Leisure } & \text { Hypoarousal } & \text { Challenges engaging in } \\ \text { Participation } & \text {-refusal to participate, minimal effort } & \begin{array}{l}\text { activities such as hiking } \\ \text { Hyperarousal } \\ \text {-destruction of property, aggressive behavior }\end{array} \\ & \end{array}$

\section{The Role of Routine for Arousal Regulation}

Each day the student viewed the daily communication log from the evening, night, and weekend shifts that documented the hourly status of each participant. This provided relevant data regarding activities completed, the names of the participants who joined, and significant statements or reactions during each activity. The daily communication log was especially relevant for the examination of routines, which led to thoughtful analysis of how the established routines and resulting arousal levels supported or hindered overall occupational participation.

\section{Need for Self-Regulation Training}

Although the student was not able to complete formal interviews, she engaged in daily conversations with the staff members and inquired about their observations regarding ways the participants self-regulated on a daily basis and how that impacted the quality of occupational engagement. Many staff reported that the participants no longer had access to the self-regulatory strategies on which they had depended before coming to the STRTP, such as drugs and alcohol. In her self-report, one participant indicated that she had trouble falling asleep because she was sober for the first time in years and did not know how to calm her body and mind without the use of substances. During a crisis intervention training, a staff member referred to ways the participants sought out regulation strategies when she stated, "They don't know how to meet needs in a normal way" (Anonymous, personal communication, October 5, 2020). Through these conversations and many others, the student identified a lack of knowledge in the participants and various staff members in how to support self-regulation in a constructive, practical, and positive manner. 
The staff conveyed feeling overwhelmed by the need for constant de-escalation and crisis intervention. Many stated they wanted various crisis intervention strategies that were proactive and wouldn't lead to restraint. There was mixed understanding among the staff of how sensorybased approaches and environmental modifications could be used as a proactive measure throughout a typical day for regulatory purposes.

\section{Program Planning Model}

Following the site-based needs assessment, it was determined that the establishment of meaningful routines that focus on regulating arousal levels would work to improve occupational participation in areas of sleep preparation and participation, feeding/eating, leisure, social participation, and participation in education. According to the OTPF (2014), routines are "patterns of behavior that are observable, regular, and repetitive and that provide structure for daily life" (p. S27). Each of the occupations listed were part of the participants' daily routine, but yet they struggled to stay engaged in the identified occupations largely in part to dysregulated arousal states. Program development therefore centered on the establishment of meaningful sensory-based routines prior to participation in each occupation, with focus on altering or maintaining arousal levels to support optimal engagement.

Program development was based off a logic model (see Appendix B) and grounded in the framework of MOHO and Dunn's sensory processing model. Short-term goals focus on identifying meaningful activities that change arousal states and applying knowledge of sensory preferences into daily routines. Long-term goals include independent application of sensorybased strategies into daily routines to improve self-regulation and lifelong participation in daily life activities.

The 7-week program (see Table 4) addresses four main topics a) education regarding the autonomic nervous system, b) sensory approaches to self-regulation, c) creation of routines, d) 
environmental modifications. The first 2 weeks focus on education regarding the ANS by considering how occupations activate either the SNS or PNS, leading to higher or lower energy states. The third week focuses on identifying sensory preferences and tendencies in order to understand how each individual self-regulates. Week 4 provides a framework of three energy levels (Chill State, Focused State, and Hyped-Up State) and helps the participants identify meaningful sensory and occupation-based activities to help them achieve the desired energy state. Week 5 applies the strategies identified in the previous weeks into a sleep routine. The sixth week applies the strategies and concepts into a study routine. The final component of the programming consists of suggestions for environmental modifications and ways to realistically create sensory supportive spaces that are conducive of independent self-regulation.

\section{Table 4}

Breakdown of 7-week program

\begin{tabular}{lll}
\hline Week & Topics Covered & Activities \\
\hline 1 & $\begin{array}{l}\text { Occupations + Our Autonomic Nervous } \\
\text { System }\end{array}$ & $\begin{array}{l}\text { Song Playlist, SNS Handout, PNS } \\
\text { Handout }\end{array}$ \\
2 & $\begin{array}{l}\text { Occupations + Our Autonomic Nervous } \\
\text { System }\end{array}$ & $\begin{array}{l}\text { Photo Challenge, Collage Creation, } \\
\text { Occupation Tracker }\end{array}$ \\
3 & Self-Regulation & 7 Senses, Ways I Self-Regulate \\
5 & Understanding Energy States & Name That State, Paint Chips \\
6 & Establishing a Seep Routine & $\begin{array}{l}\text { Would You Rather, Breakdown, My } \\
\text { Sleep Routine, Let's Talk Strategy }\end{array}$ \\
7 & Establishing a Study Routine & $\begin{array}{l}\text { Would You Rather, Breakdown, My } \\
\text { Sleep Routine, Let's Talk Strategy } \\
\text { Creating Sensory Supportive Spaces }\end{array}$ \\
\hline
\end{tabular}




\section{Chapter V: Discussion}

\section{Summary}

This capstone project sought to support community reintegration for adolescent SST through the development of sensory and occupation-based programming that fosters selfregulation, a skill foundational for lifelong occupational engagement. Following the acquisition of self-regulatory skills in the 7-week program, adolescent SST can self-identify early signs of dysregulation and immediately apply sensory-based strategies to maintain an arousal state that supports daily life engagement. The programming focused on expanding established regulation strategies that were personally meaningful and incorporating them into consistent daily routines to increase self-efficacy and occupational participation. The programming developed can be used as a tool for a variety of other therapeutic programs, safe homes, and transitional programs working alongside adolescent SST.

\section{Discussion}

There were notable differences between what the student had planned and what transpired during the capstone experience. The student had intended to complete semi-structured interviews with a variety of professionals at the STRTP. The developed questions were based off the Adolescent/Adult Sensory Profile and inquired about the survivors' sensory preferences and tendencies in order to determine how they influence patterns of behavior and participation in leisure, education, social engagement, and sleep (see Appendix C). Additional questions inquired about current programming and potential gaps where additional support may be needed in order to meet specific arousal and self-regulatory needs of SST. However, due to staffing changes at the site, formal interviews were no longer feasible. The student instead focused on clinical observations, discussion, and participation in daily activities to assess the needs of SST at the STRTP. 
To sustain the effectiveness of the programming, outcomes should be regularly measured through the modified-Canadian Occupational Performance Measure and the Quality of Life Scale. A staff and participant questionnaire will be provided at the end of each lesson to evaluate the usefulness of the programming and identify barriers in the application of sensory strategies. Adaptations to programming should be made based on these ongoing evaluations.

Although it would have been ideal to implement the program at the STRTP, the program itself provides a useful tool for dissemination across a variety of settings not just limited to SST. Since self-regulation is such a foundational skill that many adolescents have challenges in, this programming could be adapted to fit populations within schools, clinics, residential programs, and inpatient psychiatric settings.

Since an occupational therapist will not be present to directly implement the programming it is vital that staff are trained on the importance of coregulation and application of sensory strategies for arousal regulation from a trauma informed perspective. Once the foundational skill of self-regulation is established in the participants, future programming could focus on broader needs such as vocational training, community mobility, spiritual exploration, meal preparation, personal hygiene and grooming, along with financial management. It is recommended the STRTP become an emerging site for future students to continue advocating for the role of occupational therapy with this population. Grant writing could follow a proposal of an occupational therapist position at the STRTP to ensure program sustainability.

\section{Implications for Occupational Therapy}

The role of occupational therapy with adolescent SST as they transition out of trafficking and back into community life is an emerging practice area in need of advocacy. While there are well-defined needs among SST that occupational therapy can have a prominent role in meeting, 
the current role is minimal and undefined. Evidence-based sensory techniques provide a promising approach in developing essential self-regulatory skills in adolescent SST.

As sensory-based approaches are becoming a more prominent component of occupational therapy, particularly in pediatric populations with trauma backgrounds, the profession has a deep responsibility to remain occupation focused. Whenever an intervention takes a sensory-based approach, there should always be a connection to occupation. This link to occupation is the unique role occupational therapy has that distinguishes them from all other professions. Although other individuals and professions may have some knowledge on the application of sensory-based approaches, occupational therapy is able to provide a unique perspective through analysis of the cognitive, psychosocial, and environmental factors that contribute to a sensory experience and the impact this has on the individual's engagement in occupation.

\section{Conclusion}

Participation in meaningful life roles, routines, and occupations may be deeply impacted following the trafficking experience. The frequent dysregulated arousal states that accompany severe trauma has a direct impact on the reintegration process for adolescent SST. Programming that incorporates sensory-based strategies into daily routines can help to foster self-regulation and target autonomic dysregulation leading to improved occupational participation. Through empowering survivors to establish routines that support optimal occupational engagement, this program lays a lasting foundation of self-regulation that will continue to support SST as they transition out of trafficking and back into the community. 


\section{References}

Accreditation Council for Occupational Therapy Education. (2011). ACOTE standards and interpretive guide. http://www.aota.org/-/media/Corporate/Files/Education Careers/Accredit/Standards/2011-Standards-and-Interpretive-Guide.pdf

Adams-Leask, K., Varona, L., Dua, C., Baldock, M., Gerace, A., \& Muir-Cochrane, E. (2018). The benefits of sensory modulation on levels of distress for consumers in a mental health emergency setting. Australasian Psychiatry, 26(5), 514-519. https://doi.org/10.1177/1039856217751988

American Occupational Therapy Association. (2005). Complementary and alternative medicine (CAM) position paper. American Journal of Occupational Therapy, 59, 653-655.

American Occupational Therapy Association. (2014). Occupational therapy practice framework: Domain and process (3rd ed.). American Journal of Occupational Therapy, 68(Suppl. 1), S1-S48.

American Occupational Therapy Association. (2015a). Occupational therapy's role in mental health promotion, prevention, and intervention with children and youth.

https://www.aota.org/ /media/Corporate/Files/Practice/Children/Childhood-Trauma-InfoSheet-2015.pdf

American Occupational Therapy Association. (2015b). Occupational therapy's role with restraint and seclusion reduction or elimination. https://www.aota.org//media/Corporate/Files/AboutOT/Professionals/WhatIsOT/MH/Facts/Restraint $\% 20$ fact $\% 2$ $\underline{\text { 0sheet.pdf }}$

American Occupational Therapy Association. (2017). Occupational therapy using a sensory integration-approach with adult populations. https://www.aota.org/ /media/Corporate/ Files/AboutOT/Professionals/WhatIsOT/PA/Facts/SI-and-Adults-Fact-Sheet.pdf 
American Occupational Therapy Association. (2020). Occupational therapy practice framework: Domain and process (4th ed.). American Journal of Occupational Therapy, 74(Suppl. 2), 7412410010. https://doi.org/10.5014/ajot.2020.74S2001

Andersen, C., Kolmos, A., Andersen, K., Sippel, V., \& Stenager, E. (2017). Applying sensory modulation to mental health inpatient care to reduce seclusion and restraint: A case control study. Nordic Journal of Psychiatry, 71(7), 525-528. https://doi.org/10.1080/08039488.2017.1346142

Bailliard, A. L., \& Whigham, S. C. (2017). Linking neuroscience, function, and intervention: A scoping review of sensory processing and mental illness. The American Journal of Occupational Therapy: Official Publication of the American Occupational Therapy Association, 71(5), 7105100040p1-7105100040p18. https://doi.org/10.5014/ajot.2017.024497

Baldwin SB, Eisenman DP, Sayles JN, Ryan G, \& Chuang KS (2011). Identification of human trafficking victims in health care settings. Health and Human Rights, 13, E36-E49. https://pubmed.ncbi.nlm.nih.gov/22772961/

Belser, P., de Cock, M., \& Mehran, F. (2005). ILO minimum estimate of forced labour in the world. International Labour Office. https://www.ilo.org/wcmsp5/groups/public/--ed_norm/---declaration/documents/publication/wcms_081913.pdf

Bent-Goodley, T. B. (2019). Necessity of trauma-informed practice in contemporary social work. Social Work, 64(1), 5-8. https://doi.org/10.1093/sw/swy056

Blackburn, J., McKenna, B., Jackson, B., Hitch, D., Benitez, J., McLennan, C., \& Furness, T. (2016). Educating mental health clinicians about sensory modulation to enhance clinical practice in a youth acute inpatient mental health unit: A feasibility study. Issues in Mental Health Nursing, 37(7), 517-525. https://doi.org/10.1080/01612840.2 016.1184361 
Bryant, C., Freeman, L., Granata, M., He, A., Hough, H., Patel, S., Stedman, A., Silvia, A., \& Tran, M. L. (2015). Societal statement on the role of occupational therapy with survivors of human sex trafficking in the United States. Occupation: A Medium of Inquiry for Students, Faculty \& Other Practitioners Advocating for Health through Occupational Studies, 1(4). http://nsuworks.nova.edu/occupation/vol1/iss1/4

Cerny, S. (2016). The role of occupational therapy within the Federal Strategic Action Plan on Services for Victims of Human Trafficking in the United States. Occupational Therapy in Mental Health, 32(4), 317-328. https://doi.org/10/1080/0164212X.2016.1172998

Chalmers, A., Harrison, S., Mollison, K., Molloy, N., \& Gray, K. (2012). Establishing sensorybased approaches in mental health inpatient care: a multidisciplinary approach. Australasian Psychiatry: Bulletin of Royal Australian and New Zealand College of Psychiatrists, 20(1), 35-39. https://doi.org/10.1177/1039856211430146

Champagne, T. (2003). Sensory modulation and environment: Essential elements of occupation. Champagne Conferences \& Consultation.

Champagne, T. (2005). Expanding the role of sensory approaches for acute inpatient psychiatry. Mental Health Special Interest Section Quarterly, 28(1), 1-4.

Champagne, T. (2006). Sensory modulation and environment: Essential elements of occupation (2nd ed.). Champagne Conferences \& Consultation.

Champagne, T. (2010). The weighted blanket competency training program: Adult mental health populations (Order No. 3411717). Available from ProQuest Central; ProQuest Dissertations \& Theses Global. (577642570). https://search.proquest.com/dissertationstheses/weighted-blanket-competency-training-program/docview/577642570/se2? accountid $=158603$ 
Champagne, T. (2011). Sensory modulation \& environment: Essential elements of occupation (3rd ed. Rev). Pearson.

Champagne, T., \& Stromberg, N. (2004). Sensory approaches in in-patient psychiatric settings: Innovative alternatives to seclusion and restraint, Journal of Psychosocial Nursing 42, 3544. https://pubmed.ncbi.nlm.nih.gov/15493494/

Champagne, T., Ed, M., Mullen, B., \& Dickson, D. (2007). Exploring the safety \& effectiveness of the use of weighted blankets with adult populations. American Occupational Therapy Association's Annual Conference Presentation. 82. https://www.ot-innovations.com/wpcontent/uploads/2013/09/aota2007weighted_blanket_web_final_607.pdf

Champagne, T., Mullen, B., Dickson, D., \& Krishnamurty, S. (2015). Evaluating the safety and effectiveness of the weighted blanket with adults during an inpatient mental health hospitalization. Occupational Therapy in Mental Health. https://www.tandfonline.com/doi/abs/10.1080/0164212X.2015.1066220

Clawson, H. J., \& Dutch, N. (2008). Addressing the needs of victims of human trafficking: Challenges, barriers, and promising practices. U.S. Department of Health \& Human Services. http://aspe.hhs.gov/hsp/07/ HumanTrafficking/Needs/ib.shtml

Clawson, H. J., Dutch, N., Solomon, A., \& Grace, L. G. (2009). Human trafficking into and within the United States: A review of the literature. U.S. Department of Health \& Human Services. http://aspe.hhs.gov/ hsp/07/ HumanTrafficking/LitRev/index.shtml

Clawson, H. J., Small, K. M., Go, E. S., \& Myles, B. W. (2003). Needs assessment for service providers and trafficking victims. U.S. Department of Justice. https://nij.ojp.gov/library/publications/needs-assessment-service-providers-andtrafficking-victims 
Counter-Trafficking Data Collaborative. (2018.). Global data hub on human trafficking. https://www.ctdatacollaborative.org/

Cole, J., Sprang, G., Lee, R., \& Cohen, J. (2016). The trauma of commercial sexual exploitation of youth: A comparison of CSE victims to sexual abuse victims in a clinical sample. Journal of Interpersonal Violence, 31, 122-146. https://pubmed.ncbi.nlm.nih.gov/25381275/

Cole, M. B., \& Tufano, R. (2008). Applied theories in occupational therapy: A practical approach. Slack Incorporated.

Crawford, M., \& Kaufman, M. R. (2008). Sex trafficking in Nepal. Violence Against Women, 14(8), 905-916. doi:10.1177/1077801208320906

de Chesnay, M. (2013). Psychiatric-mental health nurses and the sex trafficking pandemic. Issues in Mental Health Nursing, 34(12), 901-907. doi:10.3109/01612840.2013.85720

Deshpande, N. A., \& Nour, N. M. (2013). Sex trafficking of women and girls. Reviews in Obstetrics and Gynecology, 6(1), 22-27. https://www.ncbi.nlm.nih.gov/pmc/articles/PMC3651545/

Dovydaitis, T. (2010). Human trafficking: The role of the health care provider. Journal of Midwifery \& Women's Health, 55(5), 462-467. https://doi.org/10.1016/j.jmwh.2009.12.017 Edelson, S. M., Edelson, M. G., Kerr, D. C., \& Grandin, T. (1999). Behavioral and physiological effects of deep pressure on children with autism: a pilot study evaluating the efficacy of Grandin's Hug Machine. The American Journal of Occupational Therapy: Official Publication of the American Occupational Therapy Association, 53(2), 145-152. https://doi.org/10.5014/ajot.53.2.145 
Evans, H. (2019). From the voices of domestic sex trafficking survivors: experiences of complex trauma \& posttraumatic growth. Doctorate in Social Work Dissertations. 126. https://repository.upenn.edu/edissertations_sp2/126

Fertel-Daly, D., Bedell, G., \& Hinojosa, J. (2001). The effects of the weighted vest on attention to task and self-stimulatory behaviors in preschoolers with pervasive developmental disorders. American Journal of Occupational Therapy, 55, 629-640. https://pubmed.ncbi.nlm.nih.gov/12959227/

Fisher, J. (2005). Trauma and the body: Implications for treatment. Massachusetts Department of Mental Health grand rounds presentation, Hoagland-Pincus Conference Center.

Ford, J.D., \& Blaustein, M.E. (2013). Systemic self-regulation: A framework for traumainformed services in residential juvenile justice programs. Journal of Family Violence, 27(8). https://healingattention.org/wp-content/uploads/Systemic_SelfRegulation_A_Fr.pdf

Forsyth, A. S., \& Trevarrow, R. (2018). Sensory strategies in adult mental health: A qualitative exploration of staff perspectives following the introduction of a sensory room on a male adult acute ward. International Journal of Mental Health Nursing, 27(6), 1689-1697. https://doi.org/10.1111/inm.12466

Gardner, J. (2016). Sensory modulation treatment on a psychiatric inpatient unit: Results of a pilot program. Journal of Psychosocial Nursing and Mental Health Services, 54(4), 4451. https://doi.org/10.3928/02793695-20160318-06

Gorman, K. W., \& Hatkevich, B. A. (2016). Role of occupational therapy in combating human trafficking. American Journal of Occupational Therapy, 70(6), 7006360010p17006360010p6. https://doi.org/10.5014/ajot.2016.016782 
Grandin, T. (1992). Calming effects of deep pressure in patients with autistic disorder, college students, and animals. Journal of Child and Adolescent Psychopharmacology, 2, 63-72. https://pubmed.ncbi.nlm.nih.gov/19630623/

Grenier, I. R., Bigsby, R., Vergara, E. R., \& Lester, B. M. (2003). Comparison of motor selfregulatory and stress behaviors of preterm infants across body positions. American Journal of Occupational Therapy, 57, 289-297. http://dx.doi.org/10.5014/ajot.57.3.289

Helfrich, C. A., Aviles, A. M., Badiani, C., Walens, D., \& Sabol, P. (2006). Life skill interventions with homeless youth, domestic violence victims and adults with mental illness. Occupational Therapy in Health Care, 20, 189-

207. https://doi.org/10.1080/J003v20n03_12

Hodgdon, H., Kinniburgh, K., Gabowitz, D., Blaustein, M., \& Spinazzola, J. (2013).

Development and implementation of trauma-informed programming in residential schools using the ARC framework. Journal of Family Violence, 27(8).

Holland, J., Begin, D., Orris, D., \& Meyer, A. (2018). A descriptive analysis of the theory and processes of an innovative day program for young women with trauma-related symptoms, Occupational Therapy in Mental Health, 34:3, 228-241. 241. https://www.tandfonline.com/action/showCitFormats?doi=10.1080\%2F0164212X.2017.1 $\underline{393369}$

Hossain, M., Zimmerman, C., Abas, M., Light, M., \& Watts, C. (2010). The relationship of trauma to mental disorders among trafficked and sexually exploited girls and women. American Journal of Public Health, 100(12), 2442-2449. https://www.ncbi.nlm.nih.gov/pmc/articles/PMC2978168/

Ismael, N., Lawson, L. M., \& Hartwell, J. (2018). Relationship between sensory processing and participation in daily occupations for children with autism spectrum disorder: A 
systematic review of studies that used Dunn's sensory processing framework. American Journal of Occupational Therapy, 72(3), 1-9. https://doi.org/10.5014/ajot.2018.024075

Judge, A. M. (2018). Uncharted waters: Developing mental health services for survivors of domestic human sex trafficking. Harvard Review of Psychiatry, 26(5), 287-297. https://doi.org/10.1097/HRP.0000000000000196

Kielhofner, G. (1985). A model of human occupation: Theory and application. Williams \& Wilkins.

Koomar, J. (2009). Trauma- and attachment-informed sensory integration assessment and intervention. American Journal of Occupational Therapy, 32(4).

Kuypers, L. M., \& Winner, M. G. (2011). The Zones of Regulation: A curriculum designed to foster self-regulation and emotional control. Social Thinking Publishing.

Lavoie, J., Dickerson, K. L., Redlich, A. D., \& Quas, J. A. (2019). Overcoming disclosure reluctance in youth victims of sex trafficking: New directions for research, policy, and practice. Psychology, Public Policy, and Law: An Official Law Review of the University of Arizona College of Law and the University of Miami School of Law, 25(4), 225-238. https://doi.org/10.1037/law0000205

LeBel, J., \& Champagne, T. (2010). Integrating sensory and trauma-informed interventions: A Massachusetts state initiative, part 2. Mental Health Special Interest Section Quarterly, $33(2), 1-4$.

LeBel, J., Champagne, T., Stromberg, N., \& Coyle, R. (2010). Integrating sensory and traumainformed interventions: A Massachusetts state initiative, part 1. Mental Health Special Interest Section Quarterly, 33(1), 1-4 http://tnoys.org/wpcontent/uploads/IntSensTICPart1.pdf

Levine, P., Frederick, A., (1997). Walking the Tiger: Healing Trauma. North Atlantic Books. 
Lin, H.-Y., Lee, P., Chang, W.-D., \& Hong, F.-Y. (2014). Effects of weighted vests on attention, impulse control, and on-task behavior in children with attention deficit hyperactivity disorder. American Journal of Occupational Therapy, 68, 149-158. https://pubmed.ncbi.nlm.nih.gov/24581401/

Lindholm J, Börjesson M, \& Cederborg A-C (2014). "What happened when you came to Sweden?": Attributing responsibility in police interviews with alleged adolescent human trafficking victims. Narrative Inquiry, 24, 181-199. https://doi.org/10.1075/ni.24.2.01lin

Lloyd, C., King, R., \& Machingura, T. (2014). An investigation into the effectiveness of sensory modulation in reducing seclusion within an acute mental health unit. Advances in Mental Health, 2, 93. https://www.tandfonline.com/doi/abs/10.1080/18374905.2014.11081887

Macy, R. J., \& Johns, N. (2011). Aftercare services for international sex trafficking survivors: informing U.S. service and program development in an emerging practice area. Trauma, Violence \& Abuse, 12(2), 87-98. https://doi.org/10.1177/1524838010390709

Maney, G. M., Brown, T., Gregory, T., Mallick, R., Simoneschi, S., Wheby, C., Wiktor, N. (2011). Meeting the service needs of human trafficking survivors in the New York City metropolitan area: Assessment and recommendation. http://lifewaynetwork.org/wpcontent/uploads/2011/11/Hofstra-University-LifeWay-Network-Report-2011.pdf

Martin, E. (2015). Trauma-informed programming: Occupation-based groups for adolescent sex trafficking survivors. [Entry-Level OTD Capstones, Pacific University]. https://commons.pacificu.edu/otde/4

Martini, R., Cramm, H., Egan, M., \& Sikora, L. (2016). Scoping review of self-regulation: What are occupational therapists talking about? American Journal of Occupational Therapy, 6 . https://doi.org/10.5014/ajot.2016.020362 
Miller, L., Reisman, J., McIntosh, D., \& Simon, J. (2001). An ecological model of sensory modulation. In S. S. Roley E. Blanche, \& R. Schaaf (Eds.), Understanding the nature of integration with diverse populations (pp. 57-82). Therapy Skill Builders.

Moore, K. M., \& Henry, A. D. (2002). Treatment of adult psychiatric patients using the Wilbarger protocol. Occupational Therapy in Mental Health, 18(1), 43-63. https://doi.org/10.1300/J004v18n01_03

Mullen, B., Champagne, T., Krishnamurty, S., Dickson, D., \& Gao, R. X. (2008). Exploring the safety and therapeutic effects of deep pressure stimulation using a weighted blanket. Occupational Therapy in Mental Health, 24, 65-

89. https://doi.org/10.1300/J004v24n01_05

National Association of State Mental Health Program Directors. (2009). National executive training institute curriculum for the creation of violence- free, coercion-free treatment settings and the reduction of seclusion and restraint, 7th edition. National Association of State Mental Health Program Directors, Office of Technical Assistance.

National Human Trafficking Hotline. (2014). Federal Law. https://humantraffickinghotline.or g/what-human-trafficking/federal-law

National Human Trafficking Hotline. (2018). Hotline statistics. https://humantraffickinghotline.org/states

Novak, T., Scanlan, J., McCaul, D., MacDonald, N., \& Clarke, T. (2012). Pilot study of a sensory room in an acute inpatient psychiatric unit. Australasian Psychiatry, 20(5), 401406. https://doi.org/10.1177/1039856212459585

Ogden, P., \& Minton, K. (2000). Sensorimotor psychotherapy: One method for processing traumatic memory. Traumatology, 6(3), 1-21. 
Olson, L. J., \& Moulton, H. J. (2004a). Occupational therapists' reported experiences using weighted vests with children with specific developmental disorders. Occupational Therapy International, 11, 52-66. https://pubmed.ncbi.nlm.nih.gov/15118771/

Olson, L. J., \& Moulton, H. J. (2004b). Use of weighted vests in pediatric occupational therapy practice. Physical \& Occupational Therapy in Pediatrics, 24, 45-60. https://pubmed.ncbi.nlm.nih.gov/15257968/

Oram, S., Stockl, H., Busza, J., Howard, L. M., \& Zimmerman, C. (2012). Prevalence and risk of violence and the physical, mental, and sexual health problems associated with human trafficking: Systematic review. PLoS Medicine, 9, e1001224. https://pubmed.ncbi.nlm.nih.gov/22666182/

Orme, J., \& Ross-Sheriff, F. (2015). Sex trafficking: Policies, programs, and services. Social Work, 60(4), 287-294. https://doi.org/10.1093/sw/swv031

Pfeiffer, B. (2012). Sensory hypersensitivity and anxiety: The chicken or the egg? Sensory Integration Special Interest Section Quarterly, 35(2), 1-2.

Reid, J. A. (2016). Entrapment and enmeshment schemes used by sex traffickers. Sexual Abuse: Journal of Research and Treatment, 28(6), 491-511. https://doi.org/10.1177/ 1079063214544334.

Reynolds, S., Lane, S. J., \& Mullen, B. (2015). Brief report: Effects of deep pressure stimulation on physiological arousal. American Journal of Occupational Therapy, 69, 6903350010p16903350010p5. https://pubmed.ncbi.nlm.nih.gov/25871605/

Sanchez, R. V., Speck, P. M., \& Patrician, P. A. (2019). A concept analysis of trauma coercive bonding in the commercial sexual exploitation of children. Journal of Pediatric Nursing: 
Nursing Care of Children and Families, 46, 48-54.

https://doi.org/10.1016/j.pedn.2019.02.030

Shin, L. M., McNally, R. J., Kosslyn, S. M., Thompson, W. L., Rauch, S. L., Alpert, N. M., Metzger, L. J., Lasko, N. B., Orr, S. P., \& Pitman, R. K. (1999). Regional cerebral blood flow during script-driven imagery in childhood sexual abuse-related PTSD: A PET investigation. The American journal of psychiatry, 156(4), 575-584. https://pubmed.ncbi.nlm.nih.gov/10200737/

Smith, S. A., Press, B., Koenig, K. P., \& Kinnealey, M. (2005). Effects of sensory integration intervention on self-stimulating and self-injurious behaviors. American Journal of Occupational Therapy, 59, 418-425. https:/pubmed.ncbi.nlm.nih.gov/16124208/

Snider, J. (2012, May). Facilitating rest for victims of sex trafficking at Genesis Project Safe House (Master's thesis). University of Puget Sound, WA, Department of Occupational Therapy. https://core.ac.uk/download/pdf/216861669.pdf

Stoller, C. C., Greuel, J. H., Cimini, L. S., Fowler, M. S., \& Koomar, J. A. (2012). Effects of sensory-enhanced yoga on symptoms of combat stress in deployed military personnel. American Journal of Occupational Therapy, 66(1), 59-68. http://dx.doi.org/10.5014/ajot.2 $\underline{012.001230}$

Sutton, D., \& Nicholson, E. (2012). Sensory modulation in acute mental health wards: a qualitative study of staff and service user perspectives. The National Centre of Mental Health Research, Information and Workforce Development. http://openrepository.aut.ac.nz/handle/10292/4312

Swaner, R., Labriola, M., Rempel, M., Walker, A., \& Spadafore, J. (2016). Youth Involvement in the Sex Trade: A National Study. 166.

https://www.ncjrs.gov/pdffiles1/ojjdp/grants/249952.pdf 
Talens, C., \& Landman, C. (2003). Good practices on (re)integration of victims of trafficking in human beings in six European countries. Bonded Labour in the Netherlands: Anti Trafficking Program. 93. https://lastradainternational.org/lsidocs/143\%20Goodpracticeson (re)integration\%20(BliNn).pdf

Thompson, T. (2017). Community living integration club for women in recovery from sex trafficking. 94. https://nsuworks.nova.edu/cgi/viewcontent.cgi?article=1050\&c ontext=hpd_ot_student_dissertations

Thompson, T., Flick, J., \& Thinnes, A. (2020). Occupational injustice and human trafficking: Occupational therapy's role. 10. https://www.aota.org//media/Corporate/Files/Publications/CE-Articles/CEA_January_2020.pdf

Tsutsumi, A., Izutsu, T., Poudyal, A. K., Kato, S., \& Marui, E. (2008). Mental health of female survivors of human trafficking in Nepal. Social Science \& Medicine, 66(8), 18. https://pubmed.ncbi.nlm.nih.gov/18276050/

United Nations Office on Drugs and Crime. (2009). Model law against trafficking in persons. United Nations Press. https://www.unodc.org/documents/humantrafficking/UNODC_Model_Law_on_Trafficking_in_Persons.pdf

United States Department of Health and Human Services, Substance Abuse and Mental Health Services Administration. (2003). A national call to action: Eliminating the use of seclusion and restraint. USDHHS.

United States Department of State. (2000). Victims of Trafficking and Violence Protection Act of 2000. http://www.state.gov/j/tip/laws/61124.htm van der Kolk, B. (2005). Child abuse and victimization. Psychiatric Annals, 35, 374-378. https://cachouston.org/wp-content/uploads/2018/12/Child-Abuse-and-Victimization.pdf 
van der Kolk, B. (2006). Clinical implications of neuroscience research and PTSD. Animals of the New York Academy of Science, 1071, 277-293. https://pubmed.ncbi.nlm.nih.gov/16891578/

van der Kolk, B. (2004). The psychobiology of posttraumatic stress disorder. In J. Panksepp (Ed.), Textbook of biological psychiatry (pp. 319-344). Wiley.

van der Kolk, B. (2015). The body keeps the score: Brain, mind, and body in the healing of trauma. Penguin Books.

Warner, E., Koomar, J., Lary, B., \& Cook, A. (2013). Can the body change the score? Application of sensory modulation principles in the treatment of traumatized adolescents in residential settings. Journal of Family Violence, 28(7), 729-738. https://link.springer.com/article/10.1007/s10896-013-9535-8

Warner, E. Spinazzola, J. Westcott, A., Gunn, C., \& Hodgdon, H. (2014) The body can change the score: Empirical support for somatic regulation in the treatment of traumatized adolescents. Journal of Child \& Adolescent Trauma, 7(4), 237-246.

Westcott, A., Warner, E., Finn, H., \& Cook, A. (2018). What is SMART Treatment. https://smartmovespartners.com/what-is-smart-treatment/

Williams, M. S. \& Shellenberger, S. (1994). The Alert Program for self-regulation. American Occupational Therapy Association Sensory Integration Special Interest Section Newsletter, 17, 1-3.

Williamson, E., Dutch, N., \& Clawson, H. (2008). Evidence-based mental health treatment for victims of human trafficking. U.S. Department of Health and Human Services, Office of the Assistant Secretary for Planning and Evaluation. https://aspe.hhs.gov/pdfreport/evidence-based-mental-health-treatment-victims-human-trafficking 
Wylie, M. S. (2004). The limits of talk. Psychotherapy Networker, 28(1), 30-36.

http://www.traumacenter.org/Networker.pdf

Zimmerman, C., Hossain, M., \& Watts, C. (2011). Human trafficking and health: A conceptual model to inform policy, intervention and research. Social Science \& Medicine, 73(2), 327335. https://doi.org/10.1016/j.socscimed.2011.05.028

Zimmerman, C., Hossain, M., Yun, K., Gajdadziev, V., Guzun, N., Tchomarova, M., Ciarrocchi, R. A., Johansson, A., Kefurtova, A., Scodanibbio, S., Motus, M. N., Roche, B., Morison, L., \& Watts, C. (2008). The health of trafficked women: a survey of women entering post trafficking services in Europe. American Journal of Public Health, 98(1), 55-59. https://www.ncbi.nlm.nih.gov/pmc/articles/PMC2156078/

Zimmerman, C., Hossain, M., Yun, K., Roche, B., Morison, L., \& Watts, C. (2006). Stolen smiles: The physical and psychological health consequences of women and adolescents trafficked in Europe. London School of Hygiene \& Tropical Medicine. https://researchonline.lshtm.ac.uk/id/eprint/10783 
Table 2

Themes Identified from Needs Assessment

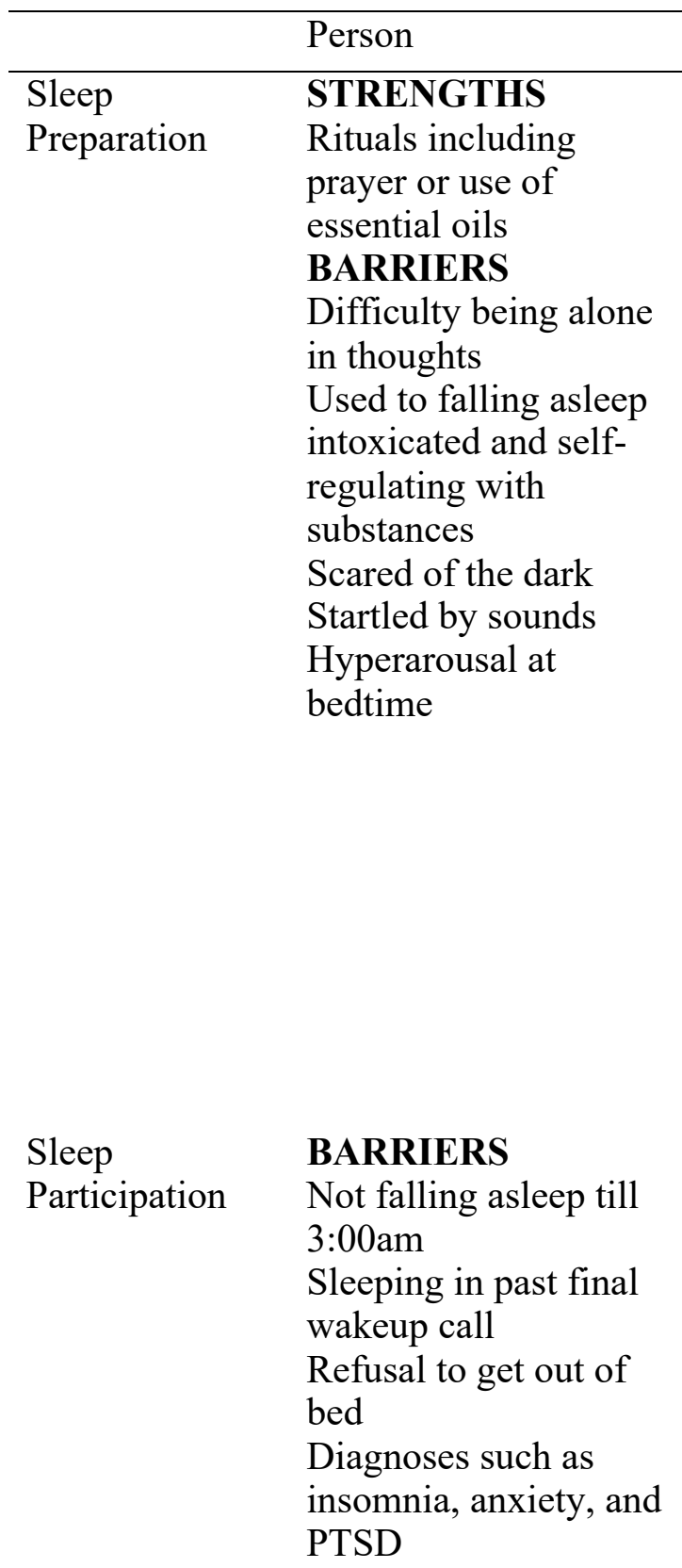

Participation in

Education

Environment
STRENGTHS
Flexibility in roommate
assignments
No more than two
residents per room
BARRIERS
Multiple sets of staffing
(Sun-Wed, Thurs-Sat)
Staff shift change at
bedtime
Continual room checks
by staff every 15 minutes
throughout the night
Wearing daytime clothes
to bed

Occupation

STRENGTHS

Participation in

meaningful activities after

lights-out including

journaling, listening to

music, and drawing

Consistent evening

routine

BARRIERS

No individualized

bedtime routines

Alerting activities in

evening routine:

${ }^{\circ}$ Phone calls to case workers, lawyers, friends, or family which were often upsetting

${ }^{\circ}$ Group meeting to reflect on highs and lows of the day

${ }^{\circ}$ Behavior review as the last activity before bed

\section{STRENGTHS \\ Work well with 1-1 \\ support \\ Motivated by specific \\ career paths \\ BARRIERS \\ STRENGTHS \\ Two rooms available \\ Schedule flexibility \\ Higher staff to student ratio than a traditional classroom at $4: 1$}

Refusal to participate

\section{STRENGTHS}

Scheduled and frequent

breaks

Access to meaningful activities such as journaling, braiding hair, or socializing 


\begin{tabular}{|c|c|c|c|}
\hline & Person & Environment & Occupation \\
\hline & $\begin{array}{l}\text { Hyperarousal and } \\
\text { hypoarousal making } \\
\text { concentration and } \\
\text { learning difficult } \\
\text { Limited attention span } \\
\text { Low motivation } \\
\text { Education not seen as } \\
\text { the path to success } \\
\text { Interests in other } \\
\text { avenues such as the } \\
\text { arts or trade school } \\
\text { Anxiety surrounding } \\
\text { school participation, } \\
\text { low success in the past } \\
\text { Diagnoses such as } \\
\text { ADHD, anxiety, } \\
\text { depression, } \\
\text { oppositional defiant } \\
\text { disorder }\end{array}$ & $\begin{array}{l}\text { Able to work at their own } \\
\text { pace with flexible } \\
\text { deadlines } \\
\text { Nontraditional classroom } \\
\text { setup } \\
\text { Peer support available } \\
\text { BARRIERS } \\
\text { Lack of staff } \\
\text { understanding of how to } \\
\text { support an IEP } \\
\text { Loud and chaotic } \\
\text { classroom } \\
\text { Large round tables } \\
\text { instead of individualized } \\
\text { desks } \\
\text { Large windows providing } \\
\text { visual distractions } \\
\text { Inconsistent classroom } \\
\text { schedule due to non- } \\
\text { school related } \\
\text { appointments } \\
\text { Staff not always } \\
\text { available for 1-1 support } \\
\text { when needed } \\
\text { Frequent staff } \\
\text { intervention and de- } \\
\text { escalation }\end{array}$ & $\begin{array}{l}\text { BARRIERS } \\
\text { Constant body movement } \\
\text { Taking naps or falling } \\
\text { asleep in class } \\
\text { Getting up from seat } \\
\text { frequently to walk around } \\
\text { the room } \\
\text { Need for coregulation } \\
\text { from staff } \\
\text { Participation in activities } \\
\text { that are distracting to the } \\
\text { classroom environment } \\
\text { Staff's perceptions of } \\
\text { participation in } \\
\text { meaningful activities } \\
\text { during class } \\
\text { Minimal daily } \\
\text { requirements for school } \\
\text { matched with an } \\
\text { abundance of class time }\end{array}$ \\
\hline Feeding/Eating & $\begin{array}{l}\text { BARRIERS } \\
\text { Daily meal refusals } \\
\text { Hyperarousal } \\
\text { Hypoarousal } \\
\text { Poor interoceptive } \\
\text { awareness } \\
\text { Body image concerns } \\
\text { Frequent meal refusals } \\
\text { when in high arousal } \\
\text { states such as after } \\
\text { court hearings, family } \\
\text { meetings, or calls with } \\
\text { a social worker }\end{array}$ & $\begin{array}{l}\text { STRENGTHS } \\
\text { Alternate meal options } \\
\text { Snacks always available } \\
\text { Indoor and outdoor } \\
\text { eating locations } \\
\text { BARRIERS } \\
\text { Prior food insecurity } \\
\text { Meal refusals following a } \\
\text { house fight or crisis }\end{array}$ & $\begin{array}{l}\text { STRENGTHS } \\
\text { Participation in } \\
\text { meaningful activities } \\
\text { during mealtimes such as } \\
\text { listening to music, } \\
\text { socializing, or journaling } \\
\text { BARRIERS } \\
\text { Not eating during } \\
\text { designated meal times but } \\
\text { eating secretly or alone } \\
\text { later } \\
\text { Sneaking or stealing food } \\
\text { to eat later }\end{array}$ \\
\hline
\end{tabular}




\begin{tabular}{|c|c|c|c|}
\hline & Person & Environment & Occupation \\
\hline $\begin{array}{l}\text { Social } \\
\text { Participation }\end{array}$ & $\begin{array}{l}\text { STRENGTHS } \\
\text { Shared interests with } \\
\text { peers } \\
\text { BARRIERS } \\
\text { Difficulty engaging } \\
\text { with others when in } \\
\text { low arousal states } \\
\text { Frequent conflict or } \\
\text { aggression when in } \\
\text { high arousal states }\end{array}$ & $\begin{array}{l}\text { STRENGTHS } \\
\text { Current programming } \\
\text { provides many fun } \\
\text { opportunities for } \\
\text { engagement } \\
\text { BARRIERS } \\
\text { Frequent staff } \\
\text { intervention and de- } \\
\text { escalation } \\
\text { Lack of desire to be } \\
\text { around others who are in } \\
\text { escalated arousal states }\end{array}$ & $\begin{array}{l}\text { STRENGTHS } \\
\text { Many opportunities for } \\
\text { engagement }\end{array}$ \\
\hline $\begin{array}{l}\text { Leisure } \\
\text { Participation }\end{array}$ & $\begin{array}{l}\text { STRENGTHS } \\
\text { Regular involvement } \\
\text { and enjoyment by } \\
\text { most participants } \\
\text { BARRIERS } \\
\text { Aggressive behavior } \\
\text { Destruction of } \\
\text { property } \\
\text { Hyperarousal } \\
\text { Hypoarousal } \\
\text { Low participation } \\
\text { Activities such as } \\
\text { sports or hiking } \\
\text { difficult to engage in } \\
\text { while in low arousal } \\
\text { states } \\
\text { Activities such as } \\
\text { reading or painting } \\
\text { challenging while in } \\
\text { high arousal states }\end{array}$ & $\begin{array}{l}\text { STRENGTHS } \\
\text { Variety of leisure options } \\
\text { BARRIERS } \\
\text { Staff always required to } \\
\text { be present limiting time } \\
\text { spent in solidarity } \\
\text { Frequent staff } \\
\text { intervention and de- } \\
\text { escalation }\end{array}$ & $\begin{array}{l}\text { STRENGTHS } \\
\text { Access to a variety of } \\
\text { meaningful occupations } \\
\text { Volleyball courts } \\
\text { Music Room } \\
\text { Art Supplies } \\
\text { Games } \\
\text { Library } \\
\text { Hiking trails } \\
\text { Video games } \\
\text { Movies } \\
\text { Swimming pool }\end{array}$ \\
\hline
\end{tabular}




\section{Appendix A}

\section{Clinical Observation Field Notes}

\begin{tabular}{|l|l|l|l|l|l|}
\hline DATE/TIME & OCCUPATION & OBJECTIVE & SUBJECTIVE & STATEMENTS & THEME \\
\hline $11 / 22 / 20$ & $\begin{array}{l}\text { Classroom homework } \\
\text { activity }\end{array}$ & $\begin{array}{l}\text { Client completed first } \\
\text { page of history } \\
\text { assignment in 30 } \\
\text { minutes with two } \\
\text { breaks. Client required } \\
\text { three verbal cues from } \\
\text { staff to stay on task. }\end{array}$ & $\begin{array}{l}\text { Loud music coming } \\
\text { from other room } \\
\text { Dog barking outside }\end{array}$ & $\begin{array}{l}\text { "I want to finish early } \\
\text { today" } \\
\text { "I can't concentrate when } \\
\text { they are being so loud" }\end{array}$ & $\begin{array}{l}\text { Difficulty staying on } \\
\text { task, hyperarousal }\end{array}$ \\
\hline & & & & & \\
\hline & & & & & \\
\hline & & & & & \\
\hline
\end{tabular}


Appendix B- Logic Model

Community Reintegration Programming for adolescent Survivors of Sex Trafficking at a Short Term Residential Therapeutic Program

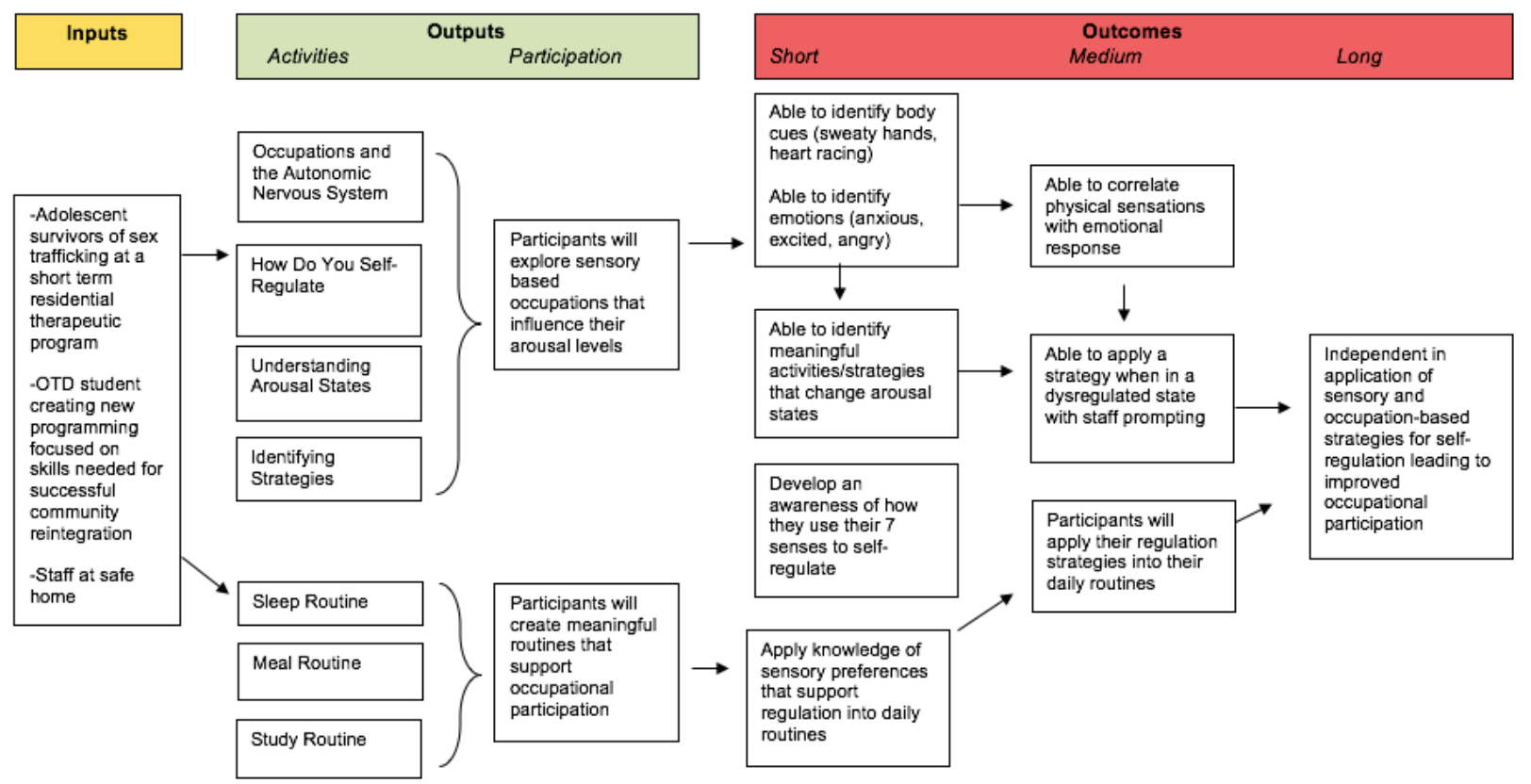

Assumptions

-SST will be open and communicative regarding their needs and experiences

-SST are experiencing challenges in occupational engagement

- There are sensory concerns impacting occupational performance
External Factors

-Other therapies and services SST receive

-Staff/volunteer

-Resourcing 


\section{Appendix C}

\section{Interview Questions}

\section{General}

1. Are you familiar with occupational therapy?

2. Have you heard of proprioceptive input? Do you know how it impacts attention?

3. Have you heard of vestibular input? Do you know how it impacts attention?

4. Do you know how fight or flight reactions hinder rational thinking?

5. Do you know the purpose of a sensory kit?

Crisis Intervention

1. What does it look like during dysregulation/crisis?

2. Are you able to anticipate it more than 30 minutes before it occurs?

3. If so, what do you do to intervene?

4. Does the same approach work for most girls?

5. What are the most common triggers you notice?

6. What are the most common coping skills you observe?

Sleep

1. Do you think sleep impacts their school performance?

2. What time do they typically fall asleep?

3. Do you notice high arousal levels around bedtime?

4. Do you think behavior reviews impede on their ability to quickly fall asleep?

5. What activities do they do when they are in their beds after lights out?

6. Why do you think it is so difficult for them to fall asleep at night?

\section{Leisure}

1. Do you notice a change in quality or quantity of sleep on weekends? If so, what factors do you think contribute to that change?

2. Are certain afternoon activities more calming? Any that are alerting?

3. What activities do the girls prefer? Why do you think that is?

School

1. What would make the physical environment more positive?

2. Are there sounds, objects, textures in the school environment that may be distracting?

3. Any that are supportive?

4. Do you think music (as the girls use it) is conductive to learning?

5. Do you feel the current coping skills are productive and conducive to the classroom environment? 
Appendix D

Deliverables for Staff

Please contact the author for access to program details. 


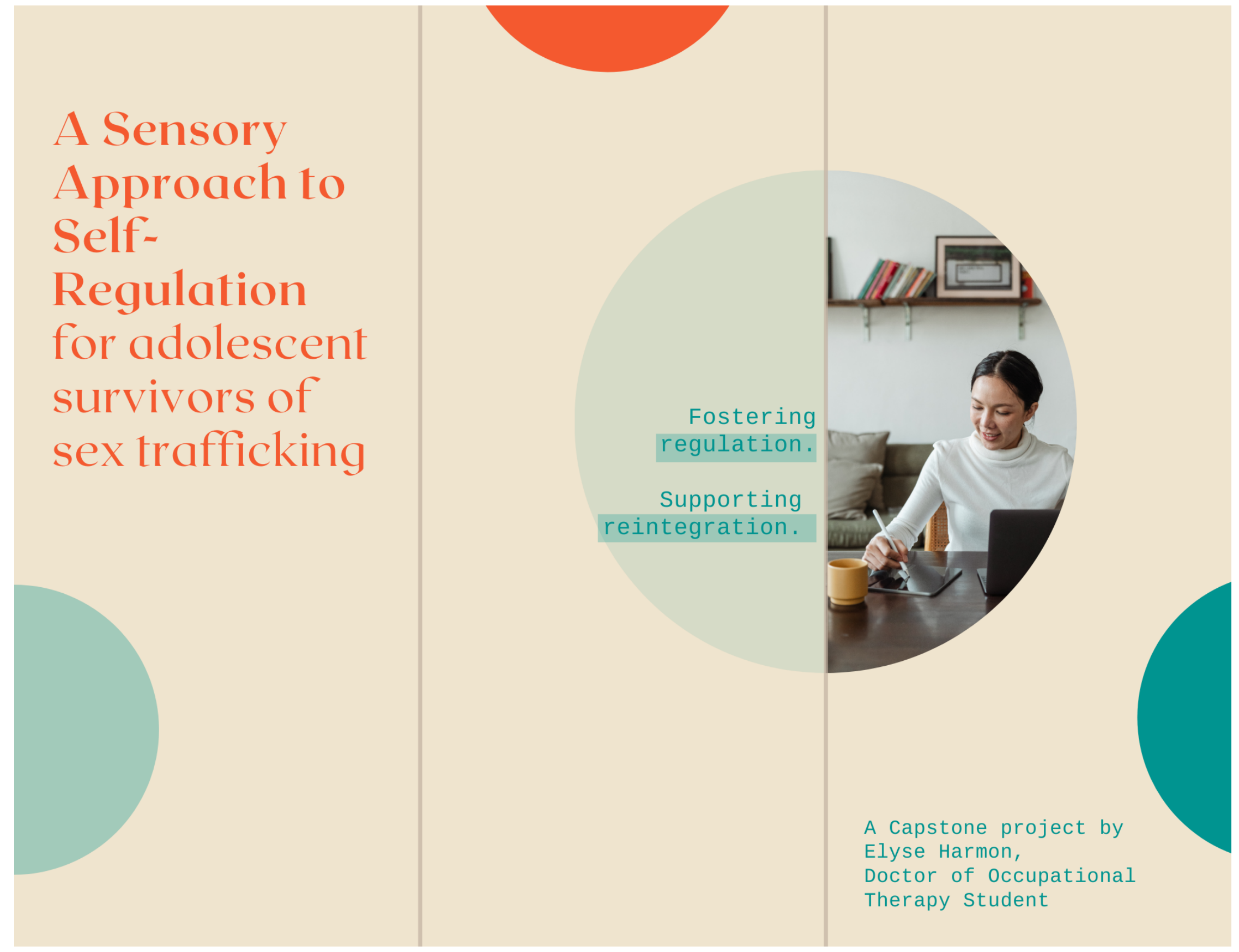




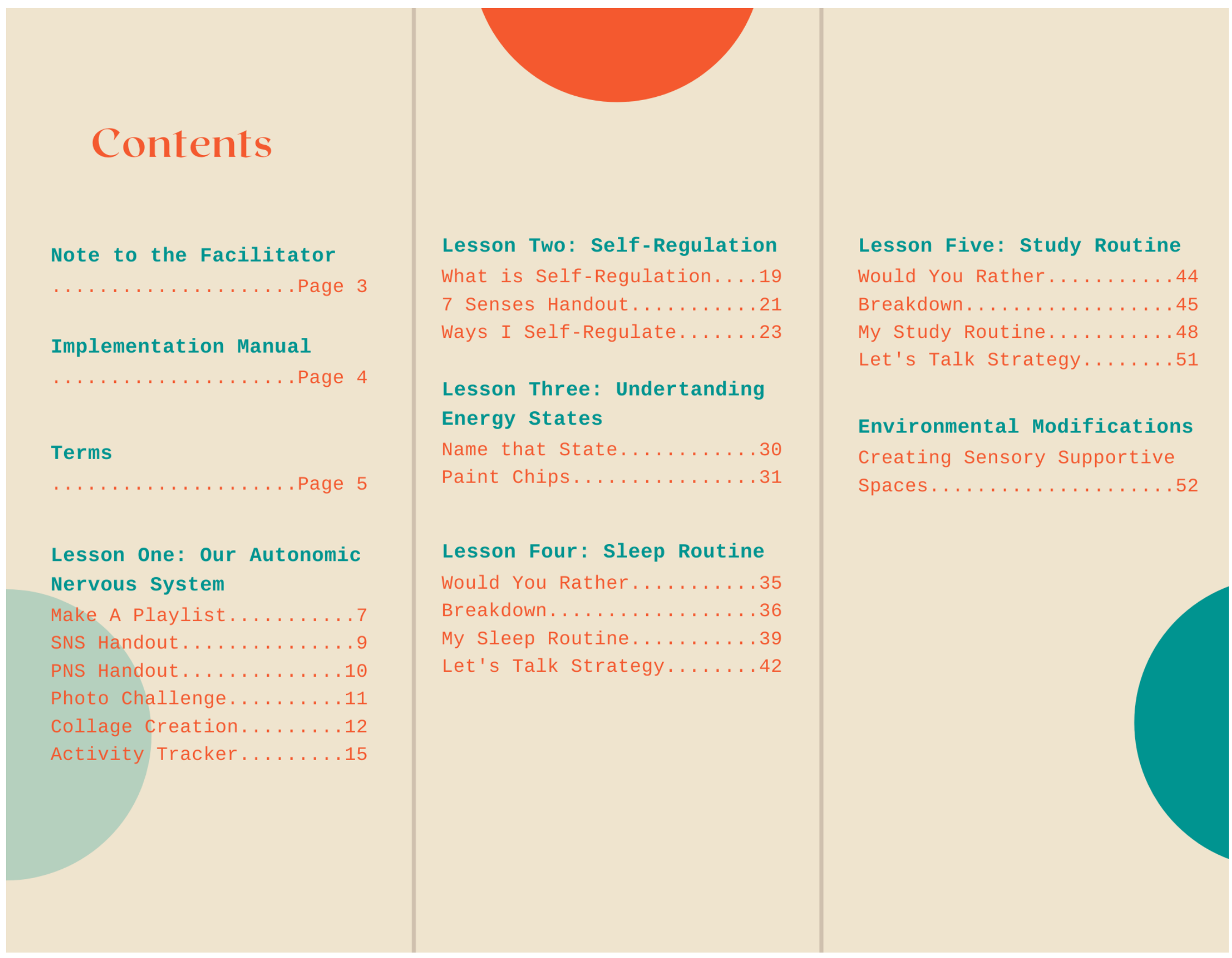

